\title{
Integration of microbial reductive dehalogenation with persulfate activation and oxidation (Bio-RD-PAO) for complete attenuation of organohalides
}

\author{
Rifeng Wu, Shanquan Wang (ه) \\ Environmental Microbiomics Research Center, School of Environmental Science and Engineering, Guangdong Provincial Key Laboratory of \\ Environmental Pollution Control and Remediation Technology, Southern Marine Science and Engineering Guangdong Laboratory (Zhuhai), \\ Sun Yat-sen University, Guangzhou 510006, China
}

\section{H I G H L I G H T S}

- Bio-RD-PAO can effectively and extensively remove organohalides.

- Bio-RD alone effectively dehalogenate the highly-halogenated organohalides.

- PAO alone is efficient in degrading the lowlyhalogenated organohalides.

- The impacts of PAO on organohalide-respiring microbial communities remain elusive.

- Bio-RD-PAO provides a promising solution for remediation of organohalide pollution.

\section{A R T I C L E I N F O}

\section{Article history:}

Received 10 January 2021

Revised 19 April 2021

Accepted 26 April 2021

Available online 8 June 2021

\section{Keywords:}

Bio-RD-PAO

Microbial reductive dehalogenation

Persulfate

Organohalide respiration

Complete attenuation

\section{G R A P H I C A B S R A C T}

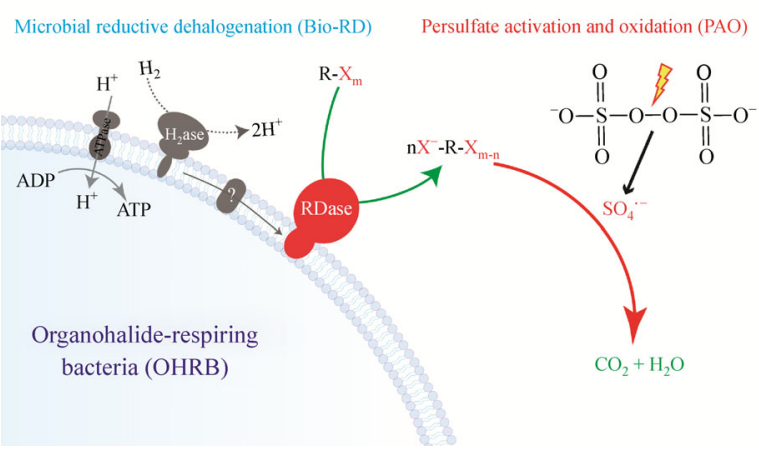

\section{A B S T R A C T}

Due to the toxicity of bioaccumulative organohalides to human beings and ecosystems, a variety of biotic and abiotic remediation methods have been developed to remove organohalides from contaminated environments. Bioremediation employing organohalide-respiring bacteria (OHRB)mediated microbial reductive dehalogenation (Bio-RD) represents a cost-effective and environmentally friendly approach to attenuate highly-halogenated organohalides, specifically organohalides in soil, sediment and other anoxic environments. Nonetheless, many factors severely restrict the implications of OHRB-based bioremediation, including incomplete dehalogenation, low abundance of OHRB and consequent low dechlorination activity. Recently, the development of in situ chemical oxidation (ISCO) based on sulfate radicals $\left(\mathrm{SO}_{4}{ }^{\circ}\right)$ via the persulfate activation and oxidation (PAO) process has attracted tremendous research interest for the remediation of lowly-halogenated organohalides due to its following advantages, e.g., complete attenuation, high reactivity and no selectivity to organohalides. Therefore, integration of OHRB-mediated Bio-RD and subsequent PAO (Bio-RD-PAO) may provide a promising solution to the remediation of organohalides. In this review, we first provide an overview of current progress in Bio-RD and PAO and compare their limitations and advantages. We then critically discuss the integration of Bio-RD and PAO (Bio-RD-PAO) for complete attenuation of organohalides and its prospects for future remediation applications. Overall, Bio-RDPAO opens up opportunities for complete attenuation and consequent effective in situ remediation of persistent organohalide pollution.

(C) The Author(s) 2021. This article is published with open access at link.springer.com and journal.hep. com.cn

\section{Introduction}

Organohalides refer to an extensive range of organic

$凶$ Corresponding author

E-mail: wangshanquan@mail.sysu.edu.cn compounds containing one or more substituted halogen atoms, including tetrachloroethylene (PCE), hexachlorobenzene (HCB), polychlorinated biphenyls (PCBs), polybrominated diphenyl ethers (PBDEs) and polychlorinated dibenzo-p-dioxins and dibenzofurans (PCDD/Fs) (Jugder et al., 2015). The massive use of these compounds in industry and agriculture, coupled with their natural 
formation results in their environmental prevalence (Fiedler, 2007; Sadowsky et al., 2013; Maucourt et al., 2020). Owing to their strong chemical stability, recalcitrance to degradation, global transfer and bioaccumulation and bioaugmentation via food webs, organohalides are raising concerns about their side effects on public health and ecosystems (Johnson-Restrepo B et al., 2005; Xu et al., 2006; Lu et al., 2019). For example, Japanese rice bran oil contaminated with PCBs and PCDFs in 1968 caused the death of 400,000 birds and 500 people (Uenotsuchi et al., 2005). In addition, the reproductive and immune function of more than half of the population of killer whales (Orcinus orca) are affected by PCBs, even though PCBs have been banned for more than 40 years (Desforges et al., 2018).

To remove organohalides from contaminated environments, many different remediation strategies have been developed, including both biotic and abiotic remediation methods: (1) physical strategies, e.g., high temperature and pressure, air sparging, electroremediation, active carbon adsorption and filtration (Ranck et al., 2005; Yang et al., 2005); (2) chemical methods, e.g., photocatalysis, metal catalysis, electrochemical catalysis and persulfate activation and oxidation (PAO) (Mascolo et al., 2008; Cai et al., 2020); and (3) biological techniques, e.g., phytoremediation and bioremediation (Wallace and Kadlec, 2005; Martinez et al., 2007). Almost all of the above-mentioned remediation methods can be conducted in situ and ex situ (pump-and-treat). In particular, in situ bioremediation employing a diverse range of organohalide-respiring bacteria (OHRB) is a comparatively effective, economical and eco-friendly way to remove organohalides from anaerobic/anoxic contaminated environmental matrices, including soil, sediment and groundwater (Heavner et al., 2019). At these anaerobic/anoxic bioremediation sites, organohalides are generally highly oxidized and electrophilic, which support OHRB-mediated organohalide respiration as electron acceptors (Wang et al., 2018; Willemin et al., 2020). Thus far, many lineages of OHRB have been identified to employ different reductive dehalogenases (RDases) to remove halogens from a variety of anthropogenic organohalides, including chloroethene, chlorophenols, chlorobenzenes, PCBs, PBDEs, PCDD/Fs and PFOCs (Fincker and Spormann, 2017; Maillard and Willemin, 2019). In their organohalide-respiring electron transport chains, OHRB employs hydrogen or organics as electron donor and organohalides as electron acceptor to harvest energy for cell growth (Atashgahi et al., 2018). Nonetheless, dehalogenation-generated organohalides become reduced and nucleophilic, which may no longer support organohalide respiration of OHRB as electron acceptors and result in accumulation of lowly-halogenated organohalides (Chen and He, 2018; Dam et al., 2019). Taking microbial reductive dechlorination of PCBs as an example, Dehalococcoides mccartyi strains (e.g., CG1,
CG4, CG5, JNA, CBDB1 and 195) as obligate OHRB dechlorinate hexa- and hepta-CBs in PCB commercial mixtures (e.g., Aroclor 1260) to di-, tri- and tetra-CBs (Adrian et al., 2009; Wang and He, 2013; LaRoe et al., 2014; Wang et al., 2014; Zhen et al., 2014), and their further dechlorination to biphenyl was seldom observed.

Chemical oxidation based on advanced oxidation processes (AOPs) with highly reactive free radicals $\left(\mathrm{OH}, 1.9-2.7 \mathrm{~V}_{\mathrm{NHE}} ; \mathrm{SO}_{4}^{--}\right.$, 2.6-3.1 $\left.\mathrm{V}_{\mathrm{NHE}}\right)$ has been extensively applied to degrade various types of recalcitrant contaminants into innocuous $\mathrm{CO}_{2}$ and $\mathrm{H}_{2} \mathrm{O}$ (Oh et al., 2016; Guvenc et al., 2021). OH is a short-lived free radical (with a half-life time of $<1 \mu \mathrm{s}$ ), which is generally produced in situ during ozone- and UV-activation of $\mathrm{H}_{2} \mathrm{O}_{2}$ or other precursors (Bokare and Choi, 2014). By contrast, the highly reactive $\left(\mathrm{V}_{\mathrm{SO} 4}{ }^{-{ }^{-}}=2.6-3.1 \mathrm{~V}_{\mathrm{NHE}} v s \mathrm{~V}_{\mathrm{OH}}{ }^{\cdot}=1.9\right.$ $2.7 \mathrm{~V}_{\mathrm{NHE}}$ ) and long lived (with a half-life time of $4 \mathrm{~s}$ ) sulfate radicals are produced in situ by cleaving the peroxide bond of persulfate molecules via energy or electron transfer reactions (Wacławek et al., 2017; Ike et al., 2018). Moreover, persulfate-AOP has the following advantages over $\mathrm{H}_{2} \mathrm{O}_{2}$-AOP: (1) a higher radical formation rate (Anipsitakis and Dionysiou, 2004; Zhiyong et al., 2013); (2) more flexible activation methods (Duan et al., 2018; Zhu et al., 2019a; Li et al., 2021); (3) less dependence on operational parameters, including $\mathrm{pH}$ and initial loading concentration (Luo et al., 2015; Lutze et al., 2015); and (4) a lower cost of persulfate production, storage and transportation, e.g., peroxydisulfate (PS) costs $\$ 0.74 / \mathrm{kg}$ in contrast to $\$ 2.2 / \mathrm{kg}$ peroxymonosulfate (PMS) and $\$ 1.5 / \mathrm{kg} \mathrm{H}_{2} \mathrm{O}_{2}$ (Zhang et al., 2014). In addition, PMS has two "dead" sulfate salts in its structure that cannot be activated, yet persulfate is stable and soluble in water, enabling wide application of persulfate (Zhang et al., 2015; Ike et al., 2018). Consequently, the comparatively longer lifetime, higher reactivity and lower cost of persulfateAOP relative to $\mathrm{H}_{2} \mathrm{O}_{2}$-AOP enable the former method to be an optimal option for the remediation of lowly-halogenated organohalides at in situ remediation sites. Consequently, PAO may complement the OHRB-mediated microbial reductive dehalogenation (Bio-RD) process for extensive cleanup of pollutants (Nam et al., 2001; Hrapovic et al., 2005; Kulik et al., 2006; Ndjou'ou et al., 2006; Sahl and Munakata-Marr, 2006; Lu et al., 2010; Venny et al., 2012; Sutton et al., 2014a; Sutton et al., 2014b; Němeček et al., 2019; Xia et al., 2020). Nonetheless, these studies employed in situ chemical oxidation (ISCO) as a pretreatment process to enhance the bioavailability and biodegradability of pollutants. In this review, we propose the consequent integration of Bio-RD and PAO (Bio-RDPAO) for complete mineralization of organohalides, and summarize recent research progress of Bio-RD and PAO, as well as their pros and cons. We also discuss the feasibility and challenges of applying Bio-RD-PAO and its prospects for future remediation applications. 


\section{Microbial reductive dehalogenation (Bio-RD)}

\subsection{Organohalide-respiring bacteria and their organohalide respiration}

Phylogenetically diverse organohalide-respiring bacteria (OHRB) employ organohalides as electron acceptors to conserve cell growth energy (Adrian and Löffler, 2016). After isolation of the first organohalide-respiring bacterium, Desulfomonile tiedjei (DeWeerd et al., 1990), extensive studies on the isolation and characterization of OHRB for their potential and limitations in the bioremediation of organohalides have resulted in a long list of wellcharacterized OHRB, which can be classified as obligate and non-obligate OHRB based on their metabolic flexibility (Hug et al., 2013; Maillard and Willemin, 2019). The obligate OHRB, including Dehalococcoides and Dehalogenimonas of Chloroflexi, are restricted to using $\mathrm{H}_{2}$ as electron donors and organohalides as electron acceptors in their respiratory electron transport chains. In contrast, non-obligate OHRB of Proteobacteria (e.g., Geobacter, Desulfuromonas, Anaeromyxobacter and Sulfurospirillum) and Firmicutes (e.g., Desulfitobacterium) are versatile in their metabolism and utilize a wide range of electron donors (e.g., hydrogen, formate and lactate) and electron acceptors (e.g., sulfate, nitrate and organohalides) for their respiration (Fincker and Spormann, 2017).

The key enzyme in OHRB to catalyze halogen removal from organohalides is reductive dehalogenase (RDase). A typical RDase homolog $(r d h)$ gene cluster contains $r d h A$ and $r d h B$ genes encoding the catalytic subunit and a membrane-anchoring protein, respectively, as well as other regulatory genes (Türkowsky et al., 2018). For organohalide respiration, OHRB employ several sets of functional enzymes to derive and transfer electrons from $\mathrm{H}_{2}$ or other organics (e.g., dehydrogenases) to organohalides (e.g., RDases). Nonetheless, specific organohalide-respiratory electron transport chains for electron transfer from electron donors to acceptors can be grouped into quinoneindependent populations (e.g., Dehalococcoides relying on menaquinones as electron shuttles) and quinonedependent populations (e.g., non-obligate OHRB of Proteobacteria and Firmicutes) (Kublik et al., 2016; Schubert et al., 2018).

\subsection{Bio-RD of organohalides}

OHRB have multiple RDase-encoding genes and are consequently capable of removing halogens from various aliphatic and aromatic organohalides (Table 1). Chloroethenes have been widely used as industrial solvents and result in environmental contamination, of which trichloroethene (TCE) and vinyl chloride (VC) are ranked \#16 and \#4, respectively, on the Substance Priority List (SPL) (Mayer-Blackwell et al., 2017). Although phylogenetically diverse microorganisms dechlorinate chloroethenes, Dehalococcoides and Dehalogenimonas are the only isolated and characterized lineages for the complete dechlorination of chloroethenes to benign ethene (Löffler et al., 2013; Wang and He, 2013; Mao et al., 2017; Yang et al., 2017b; Marcet et al., 2018; Zhao and He, 2019). At contaminated sites, co-existing pollutants or natural matter can affect the extent of OHRB-mediated dechlorination. For example, nitrous oxide $\left(\mathrm{N}_{2} \mathrm{O}\right)$, a common pollutant in groundwater, can decrease dechlorination rates and result in incomplete dechlorination of chloroethenes (Yin et al., 2019). In addition, sulfate reduction products, as well as sulfur oxyanions (e.g., $\mathrm{S}_{2} \mathrm{O}_{3}{ }^{2-}$ and $\mathrm{SO}_{3}{ }^{2-}$ ), may inhibit microbial reductive dehalogenation (Townsend and Suflita, 1997; Heimann et al., 2005; Aulenta et al., 2007; Berggren et al., 2013). Notably, if provided with enough electron donors with prolonged incubation time, complete dechlorination of TCE can be achieved in the presence of high concentrations of sulfate (Antoniou et al., 2019). In contrast, the addition of $\mathrm{NH}_{4}{ }^{+}$accelerates DCE-to-ethene dechlorination rates and increases the abundance of OHRB (Kaya et al., 2019). Other chlorinated aliphatic compounds, including chloroethanes, chloropropanes and chlorocyclohexane (i.e., $\alpha / \beta / \gamma / \delta-H C H)$, can also be completely dechlorinated by OHRB (Table 1) (Qiao et al., 2020). Their dechlorination extent largely depend on the growth conditions of the OHRB. Under harsh conditions, environmental parameters (e.g., temperature, $\mathrm{pH}$ and co-existing heavy metals) affect the dechlorination activities of OHRB and of other functional populations (Yang et al., 2017a; Marcet et al., 2018; Puentes Jácome et al., 2019; Gushgari-Doyle and Alvarez-Cohen, 2020).

Compared with microbial reductive dehalogenation of aliphatic compounds, complete dechlorination of aromatic organohalides is more challenging, particularly for persistent organohalides, including PCBs, deca-BDE and PCDD/Fs (Bedard, 2008; Rodenburg et al., 2015; Zhu et al., 2019b). Taking the reductive dechlorination of PCBs as an example, several lineages of OHRB (e.g., Dehalococcoides, Dehalogenimonas and Dehalobacter) have been identified to couple their growth with PCB dechlorination (Fricker et al., 2014; Wang et al., 2014; Wang et al., 2015; Wang et al., 2019). These OHRB preferentially attack meta- and/or para-chlorines in PCBs, leaving orthochlorinated PCBs as dechlorination products (Wu et al., 2002; Fennell et al., 2004; Adrian et al., 2009; Wang and He, 2013; LaRoe et al., 2014; Wang et al., 2014; Zhen et al., 2014; Wang et al., 2019). Thus far, several orthochlorine-removing microcosms have been established, e.g., o-17 culture (Cutter et al., 2001; Xu et al., 2018). However, the ortho-chlorine attacking OHRB have continued to elude enrichment and isolation. The characterized OHRB can only remove chlorines from highlychlorinated PCBs (e.g., penta- to nona-CBs in commercial PCB mixtures) to lowly-chlorinated PCBs (e.g., di- to tetra-CBs), seldom to benign biphenyl (Table 1). 
Table 1 Dechlorination of typical organohalides and their associated OHRB and RDases

\begin{tabular}{|c|c|c|c|c|}
\hline Parent compounds & Daughter products & Strain & RDase & Reference \\
\hline$\overline{\text { PCE, TCE, DCE }}$ & Ethene & Dehalococcoides & $\begin{array}{c}\text { PceA, VcrA, BvcA, } \\
\text { TceA }\end{array}$ & $\begin{array}{l}\text { Wang and He, 2013; } \\
\text { Marcet et al., 2018; } \\
\text { Zhao and He, } 2019\end{array}$ \\
\hline TCE, DCE & Ethene & Dehalogenimonas & $\begin{array}{l}\text { prokka_00862, } \\
\text { prokka_02004 }\end{array}$ & Yang et al., 2017b \\
\hline$(\alpha, \beta, \gamma, \delta)-\mathrm{HCH}$ & Benzene & Dehalococcoides & ND & Bashir et al., 2018 \\
\hline Trichloroethane & Ethene & Desulfitobacterium & CtrA & Zhao et al., 2015 \\
\hline \multirow[t]{2}{*}{ Dichloroethane } & Ethene & Dehalococcoides & BvcA, VcrA & $\begin{array}{l}\text { Tang et al., 2013; } \\
\text { Parthasarathy et al., } 2015\end{array}$ \\
\hline & & Dehalogenimonas & ND & Key et al., 2017 \\
\hline Dichloropropane & Propene & Dehalogenimonas & DcpA & Martin-Gonzalez et al., 2015 \\
\hline Trichloromethane & Dichloromethane & Dehalobacter & CfrA, TmrA & Heckel et al., 2019 \\
\hline $\begin{array}{l}\text { Hepta-, Octa-, Nona-CB, } \\
\text { Aroclor } 1260\end{array}$ & $\begin{array}{l}\text { Penta-, Tetra-, } \\
\text { Tri-CB, Di-CB }\end{array}$ & Dehalococcoides & $\begin{array}{l}\text { PcbA1, PcbA4, } \\
\text { PcbA5, JNA_RD8, } \\
\text { JNA_RD11 }\end{array}$ & $\begin{array}{l}\text { Wang and He, 2013; } \\
\text { Wang et al., 2015; } \\
\text { Chen and He, 2018; } \\
\text { Yu et al., 2018; } \\
\text { Wang et al., 2019 }\end{array}$ \\
\hline $\mathrm{PeCDD}$ & DiCDD & Dehalococcoides & ND & Bunge et al., 2003 \\
\hline TeCDD & MoCDD & Dehalococcoides & CbrA & $\begin{array}{l}\text { Bunge et al., 2003; } \\
\text { Pöritz et al., } 2015\end{array}$ \\
\hline $\operatorname{TrCDD}$ & $\mathrm{DD}$ & Dehalococcoides & CbrA & Pöritz et al., 2015 \\
\hline $\mathrm{HeCDF}$ & $\mathrm{TeCDF}$ & Dehalococcoides & ND & Liu and Fennell, 2008 \\
\hline $\mathrm{TeCDF}$ & $\operatorname{TrCDF}$ & Dehalococcoides & ND & Fennell et al., 2004 \\
\hline Penta-BDE, Tetra-BDE & Diphenyl ether & Dehalococcoides & PbrA1, PbrA2, PbrA3 & Ding et al., 2017 \\
\hline Pentachlorophenol & Monochlorophenol & Desulfitobacterium & CprA3 & Bisaillon et al., 2010 \\
\hline Trichlorophenol & Monochlorophenol & Dehalobacter & ND & $\begin{array}{c}\text { Li et al., 2013; } \\
\text { Wang and He, } 2013\end{array}$ \\
\hline Hexachlorobenzene & Monochlorobenzene & Dehalobacter & ND & Nelson et al., 2014 \\
\hline Pentachlorobenzene & Benzene & Dehalobacter & ND & Nelson et al., 2014 \\
\hline TBBPA & Bisphenol A & Dehalococcoides & $\begin{array}{c}\text { CbdbA } 80, \text { CbdbA1092 } \\
\text { CbrA, CbdbA1503, }\end{array}$ & Yang et al., 2015 \\
\hline Bromophenol blue & Phenol red & Dehalogenimonas & ND & Rosell et al., 2019 \\
\hline
\end{tabular}

Notes: Abbreviations: ND, not determined; Penta-CB, pentachlorinated biphenyls; Tetra-CB, tetrachlorinated biphenyls; Octa-BDE, octabrominated diphenyl ethers; Tetra-BDE, tetrabrominated diphenyl ethers; TCE, trichloroethene; DCE, dichloroethene; VC, vinyl chloride; PeCDD, pentachlorodibenzo-p-dioxin; TeCDD, tetrachlorodibenzo-p-dioxin; TrCDD, trichlorodibenzo-p-dioxin; DiCDD, dichlorodibenzo-p-dioxin; MoCDD, monochlorodibenzo-p-dioxin; DD, dibenzo-p-dioxin; $\mathrm{HeCDF}$, hexachlorodibenzofuran; TeCDF, tetrachlorodibenzofuran; TBBPA, tetrabromobisphenol A; HCH, hexachlorocyclohexane.

$\mathrm{PCDD} / \mathrm{Fs}$ are a group of the most notorious environmental pollutants, particularly the extremely toxic and carcinogenic congeners with lateral 2-, 3-, 7- and 8chlorine substitutions (Bunge et al., 2003). The OHRBmediated reductive dechlorination of PCDDs typically generates less toxic or nontoxic daughter compounds, which could be further subjected to oxidation via aromatic ring cleavage (Dam et al., 2019). Several D. mccartyi strains have been identified to dechlorinate $\mathrm{PCDD} / \mathrm{Fs}$, including strains 195, CBDB1, and DCMB5 (Fig. 1). Strain 195 dechlorinates 1,2,3,7,8-PeCDD and 1,2,3,4,7,8$\mathrm{HeCDF}$ by exclusively attacking lateral chlorines, resulting in accumulation of tri- and tetra-CDD/Fs (Liu and Fennell, 2008; Zhen et al., 2014). Strain CBDB1 dechlorinates 1,2,3,7,8-PeCDD to less toxic 2,7-/2,8DiCDD via toxic $2,3,7,8-T e C D D$ as an intermediate (Bunge et al., 2003). When amended with 1,2,3,4TeCDD, strain CBDB1 dechlorinates it to $1,2,4-\operatorname{TrCDD}$, 1,3-DiCDD and 2-MoCDD (Bunge et al., 2003). The dechlorination pathways of strain DCMB5 resembled those of strain CBDB1, particularly the removal of peripheral chlorines (positions 1 and 4), leaving the 2,3DiCDD as dechlorination product of 1,2,3,4-TeCDD and 1,2,3-TrCDD (Pöritz et al., 2015). Interestingly, trace amounts of MoCDD and non-chlorinated dibenzo-pdioxin (DD) were observed as products of 1,2,4-TrCDD dechlorination (Pöritz et al., 2015). Strain DCMB5 was the first and only reported OHRB that can completely 

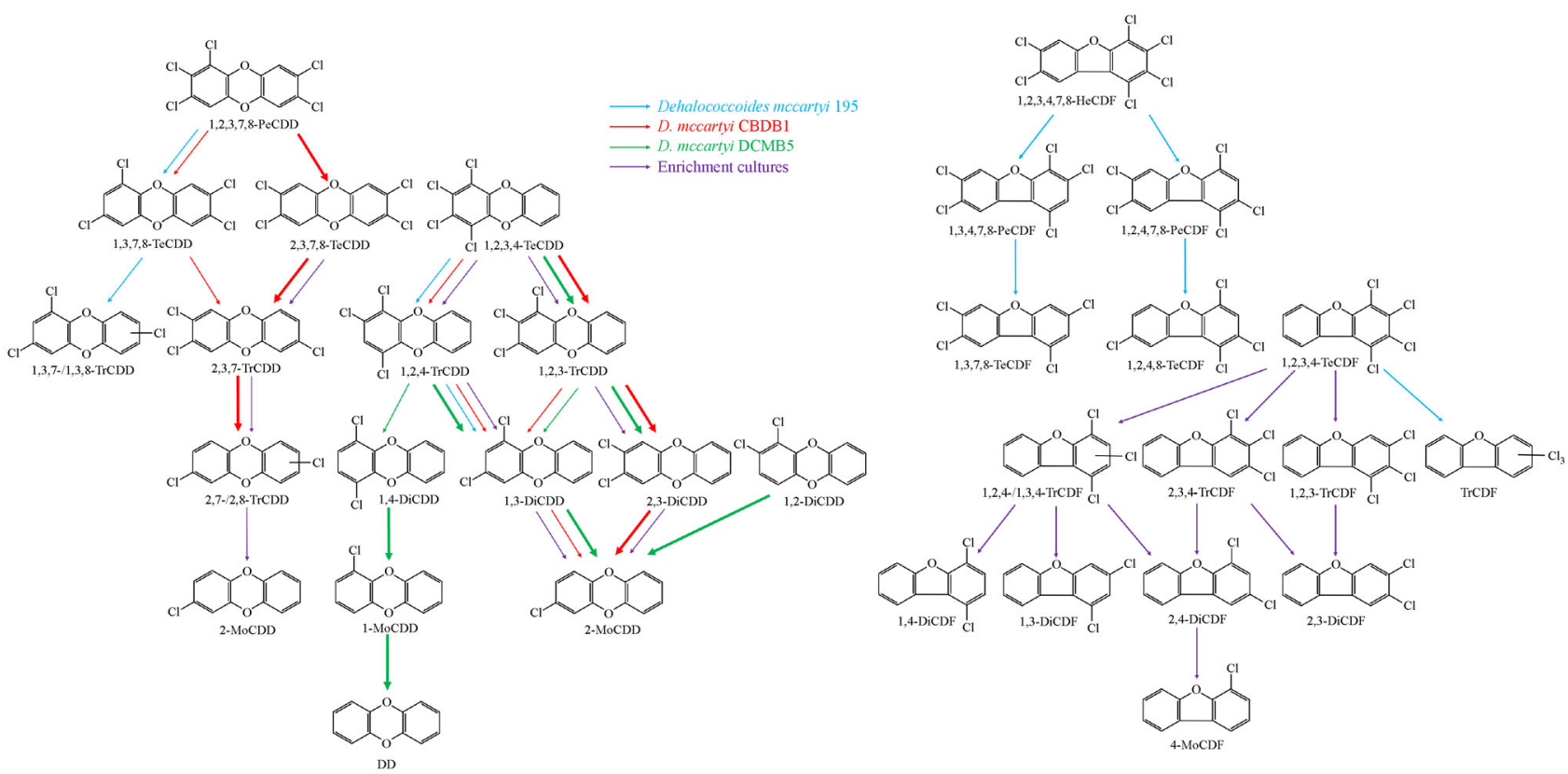

Fig. 1 Observed pathways for PCDD/Fs dechlorination in Dehalococcoides mccartyi strains and enrichment cultures. Major and minor dechlorination pathways are marked with thick and thin arrows, respectively.

dechlorinate PCDD. There are enrichment cultures showing dechlorination activities of PCDD/Fs in similar pathways with those of reported pure cultures (Liu et al., 2014a; Dam et al., 2017; Dean et al., 2020). Incomplete dechlorination of PCDD/Fs may generate highly toxic intermediates, warranting further integration of other methods to complement Bio-RD for complete dechlorination or degradation. In contrast to incomplete dechlorination of PCBs and PCDD/Fs, several other halogenated aromatic compounds could be completely dehalogenated by OHRB, including penta-BDEs to diphenyl ether (Ding et al., 2017) and pentachlorobenzene to benzene (Nelson et al., 2014). Nonetheless, these complete dehalogenation activities are limited to specific PBDEs and chlorobenzene congeners.

\subsection{Challenges in Bio-RD}

Despite the economical and eco-friendly advantages of OHRB-mediated reductive dehalogenation for the bioremediation of organohalides, its application is hindered by many challenges. OHRB may compete with indigenous populations for carbon sources, electron donors, nutrients and other growth-supporting compounds at bioremediation sites. The phase-out of fastidious OHRB could result from their long generation time and extremely narrow metabolic range (Ritalahti et al., 2005; Löffler et al., 2013; Bommer et al., 2014). The restricted metabolism of obligate OHRB has been verified by their small genomes (Siddaramappa et al., 2012; Richardson, 2013). The OHRB in Dehalococcoidia cannot synthesize corrinoid de novo as a key cofactor of RDases and they require external acetate and hydrogen to support organohalide respiration (Fincker and Spormann, 2017). Consequently, OHRB need to work closely with fermenters and acetogens to acquire essential carbon sources, electron donors, cofactors and other nutrients to support cell growth. In addition, the low bioavailability of persistent organohalides (e.g., PCBs and $\mathrm{PCDD} / \mathrm{Fs}$ ) further restricts the cell growth of OHRB. Moreover, uncertainties and complexities in biological and geochemical parameters (e.g., $\mathrm{pH}$, redox potential, temperature, salinity and co-existing pollutants) may severely inhibit OHRB activity (Lee et al., 2016). Therefore, many biostimulation and bioaugmentation strategies have been devised to guarantee dechlorination activities of OHRB at bioremediation sites (Löffler and Edwards, 2006; Sowers and May, 2013; Cervantes-Gonzalez et al., 2019), including the addition of biosurfactants, slow-releasing carbon/ nutrients and cofactors.

Nonetheless, incomplete dehalogenation is a great challenge in the OHRB-mediated bioremediation of persistent organohalides. Possible reasons for the incomplete dehalogenation include the following: (1) due to the high selectivity of RDases, OHRB attack halogens of a particular position and leave the lowly-halogenated compounds as dechlorination products (Sowers and May, 2013; Kunze et al., 2017); (2) when removing chlorines from PCBs, dechlorination compounds become more nucleophilic relative to their parent PCB substrates (Jugder et al., 2016; Williams et al., 2020); and (3) accumulation of dehalogenation intermediates may have inhibitive or other side effects on subsequent dechlorination steps (Moe et al., 
2018). The incomplete dehalogenation of organohalides results in the generation of lowly-halogenated compounds, which are nucleophilic and may be effectively degraded through oxidative processes.

\section{Persulfate activation and oxidation (PAO) for extensive degradation of organohalides}

\subsection{Principles of PAO}

PAO is an effective way to remove a variety of organic contaminants from soil, groundwater and sediment, of which persulfate activation is a crucial step. Thus far, many methods have been devised to activate persulfate, which have been extensively studied and identified with their pros and cons (Vakili et al., 2021). Compared with persulfate activation by alkali, transition metals and radiation, thermal activation and iron-/carbon-based activation are more environmentally friendly and cost-effective, being promising for field applications ( $\mathrm{Li}$ et al., 2020; Ma et al., 2021). The detailed activation methods have been comprehensively reviewed very recently (Matzek and Carter, 2016; Pang et al., 2019; Zhi et al., 2020; Karim et al., 2021; Tan et al., 2021).

Persulfate activation refers to the reaction of persulfate with an activator to form $\mathrm{SO}_{4}{ }^{--}$radicals $\left(E^{0}=2.5-3.1 \mathrm{~V}\right.$, depending on $\mathrm{pH}$; Eq. (1)) and subsequent generation of other radicals. Generally, persulfate can be activated by energy input in the form of photons (e.g., UV photolysis) and heat (e.g., thermolysis) (Fig. 2), or by direct electron transfer (e.g., metal-based and activated carbon/biocharbased electron shuttles) (Zhu et al., 2018c; Chen et al., 2019; Yao et al., 2019). Then, the newly-born $\mathrm{SO}_{4}{ }^{-1}$ radical can trigger the propagation of more $\mathrm{SO}_{4}{ }^{--}$radical through a series of chain reactions, and $\mathrm{OH}^{-}$will be generated upon the reaction between $\mathrm{SO}_{4}{ }^{--}$and $\mathrm{H}_{2} \mathrm{O} / \mathrm{OH}^{-}$(Eq. (2)). For in situ soil remediation, soil organic matter (SOM) contain various phenolic moieties as persulfate activators (Ahmad et al., 2013) and play an important role in persulfate activation (Ahmad et al., 2010). Two mechanisms have been proposed for the soil phenoxide activation of persulfate, i.e., direct electron transfer from phenoxide to persulfate (Eq. (3)) (Behrman, 2006), and nucleophilic attack of persulfate by phenoxide to generate $\mathrm{HO}_{2}$ (Eq. (4)) and subsequent electron transfer from $\mathrm{HO}_{2}^{-}$to persulfate (Eq. (5)) (Watson and Serban., 1995; Behrman, 2006). The formation of free radicals usually involves three steps: initiation, propagation and termination (Petri et al., 2011). The initiation step generally includes persulfate activation with activators for the formation of $\mathrm{SO}_{4}{ }^{--}$and other reactive radicals by radical chain reactions (Devi et al., 2016). The propagation step contains the chain reactions in which radicals extensively react with organic pollutants (Huang et al., 2002). The termination step includes removing radicals by reaction scavengers and intermediates, or by self-destruction mechanisms.

$$
\begin{aligned}
& \mathrm{S}_{2} \mathrm{O}_{8}^{2-}+\text { activator } \rightarrow \mathrm{SO}_{4}^{--}+\left(\mathrm{SO}_{4}^{--} \text {or } \mathrm{SO}_{4}^{2-}\right) \\
& \mathrm{S}_{2} \mathrm{O}_{4}^{-{ }^{-}}+\mathrm{H}_{2} \mathrm{O} / \mathrm{OH}^{-} \rightarrow \mathrm{SO}_{4}^{2-}+\mathrm{OH}^{-} \\
& \mathrm{S}_{2} \mathrm{O}_{8}^{2-}+\mathrm{PhO}^{-} \rightarrow \mathrm{SO}_{4}^{--}+\mathrm{SO}_{4}^{2-}+\mathrm{PhO}_{\mathrm{ox}} \\
& \mathrm{S}_{2} \mathrm{O}_{8}^{2-}+\mathrm{PhO}^{-} \rightarrow \mathrm{HO}_{2}^{-}+2 \mathrm{SO}_{4}^{2-}+\mathrm{PhO}_{\text {product }} \\
& \mathrm{S}_{2} \mathrm{O}_{8}^{2-}+\mathrm{HO}_{2}^{-} \rightarrow \mathrm{SO}_{4}^{2-}+\mathrm{SO}_{4}^{--}+\mathrm{O}_{2}^{--}+\mathrm{H}^{+} \\
& \underset{\mathrm{O}}{\|_{\mathrm{O}}^{\mathrm{O}}-\mathrm{O}-\mathrm{O}-\underset{\mathrm{S}}{\mathrm{O}}-\mathrm{O}^{-}} \stackrel{\mathrm{O}}{\mathrm{O}}
\end{aligned}
$$

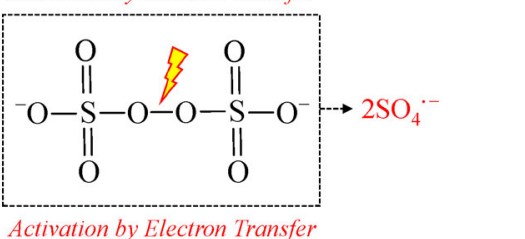

Fig. 2 Persulfate activation through electron- or energy-transfer (modified form Lee et al., 2020a).

Electron transfer in redox reactions mainly occurs by bridging mechanisms or outer-sphere mechanisms. The outer-sphere mode has a faster electron transfer rate than the bridged mechanism, due to the transient bond formation during the bridging process (Rastogi et al., 2009). In particularly, electron transfer for $\mathrm{SO}_{4}{ }^{--}$-mediated organohalide degradation mainly involves the outer-sphere mechanism, while $\mathrm{OH}^{-}$-mediated organohalide degradation involves the bridged mechanism (Monteagudo et al., 2016). In contrast to the $\mathrm{OH}^{-}$oxidization of organic matter by hydrogen abstraction or addition, $\mathrm{SO}_{4}{ }^{--}$prefers direct electron transfers and consequently more easily reacts with aromatic molecules by providing electron substituents (Mandal et al., 2018).

\subsection{PAO for organohalide degradation: pros and cons}

\subsubsection{PAO for organohalide degradation}

PAO has been applied to organohalide degradation and remediation in different environmental matrices (Table 2), including soil, sediment, surface water and groundwater, in which $\mathrm{SO}_{4}{ }^{--}$and $\mathrm{OH}$ coexist as major reactive groups for efficient degradation of lowly-halogenated organohalides 
(Pan et al., 2018). However, highly-halogenated contaminants are recalcitrant to $\mathrm{SO}_{4}{ }^{-}$-based degradation (Huang et al., 2005), including polybrominated diphenyl ethers (PBDEs), hexachloroethane (HCA), polychlorinated biphenyls (PCBs) and perfluorooctanoic acids (Teel et al., 2011; Rybnikova et al., 2016; Zhu et al., 2018b). For example, the perfluorooctanoic acids with a high oxidation state are resistance to oxidation (Wardman, 1989; Liu et al., 2012). In a previous study investigating the degradability of 51 groups of volatile organic compounds (VOCs) by $\mathrm{Fe}$ (II)-activated PAO, VOCs were classified into three classes based on their degradation efficiencies, suggesting the lower degradation rates of the higher halogenated compounds (Zhu et al., 2016a). For example, the PAO reaction rates of $\mathrm{p}$-chlorotoluene, 1,2-dichlorobenzene and 1,2,3-trichlorobenzene are $0.0024,0.00017$, and 0.00006 $\mathrm{L} / \mu \mathrm{g} / \mathrm{h}$, respectively (Zhu et al., 2016a). By contrast, the aforementioned OHRB-mediated Bio-RD mainly removes halogens from highly-halogenated organohalides. Therefore, PAO can complement Bio-RD and other strategies for extensive conversion of organohalides. Thus far, PAO has been widely employed to degrade a diverse range of organohalides (Table 2):

1) Aliphatic organohalides. PAO has emerged as an effective and efficient technique for removing chlorinated aliphatic hydrocarbons, particularly chlorinated olefins and chlorinated alkanes. For example, thermal activation of persulfate has been identified as an effective technique to remediate organohalide-contaminated groundwater, in which chlorinated olefins (e.g., PCE or TCE) and brominated alkanes (e.g., HBCD) can be degraded entirely (Waldemer et al., 2007; Yuan et al., 2014; Wu et al., 2015; Dong et al., 2019; Li et al., 2019).

2) Polychlorinated biphenyls (PCBs). The lowlychlorinated PCBs (e.g., PCB1, PCB3, PCB7, PCB8 and PCB28) can be completely mineralized to $\mathrm{CO}_{2}$ and $\mathrm{H}_{2} \mathrm{O}$ in aqueous solution at near ambient temperature (Fang et al., 2013). Nonetheless, under the same conditions, the removal efficiency of PCB30 only reached $78 \%$. Moreover, PAO-based degradation of PCB31, PCB44 and PCB153 in soil has been reported to range from $67.2 \%$ to 97.2\% after several days of incubation (Yukselen-Aksoy and Reddy, 2012; Tang et al., 2015). Therefore, PAObased PCBs degradation largely depends on both environmental matrices (e.g., water and soil) and chlorine numbers, the specific contributions of which await clarification.

3) Polybrominated diphenyl ethers (PBDEs). At an ewaste contaminated soil site with $53.8 \pm 0.5 \mathrm{mg} / \mathrm{kg}$ PBDEs (from tri- to deca-BDEs), PAO has been identified to be capable of degrading PBDEs with an efficiency of $49.5 \%$ under optimal conditions (Ma et al., 2020). In another study, $53.8 \%$ of deca-BDE (BDE-209) in soil was observed to be degraded to short-chain acids, $\mathrm{CO}_{2}$ and $\mathrm{H}_{2} \mathrm{O}$ after thermal-based PAO treatment for $360 \mathrm{~min}$ (Peng et al., 2016). Interestingly, Huang and colleagues (Huang et al., 2016) reported nearly 100\% degradation and mineralization of powdery deca-BDE by employing a mechanochemical (ball milling) activation of persulfate, involving stepwise debromination, cleavage of ether bonds and collapse of benzene rings. The strong oxidation capacity is due to the mechanochemical enhancement of persulfate activation for the production of sulfate radicals. This method provides a promising way to remove solid and highly-halogenated organohalides.

4) Dichlorodiphenyltrichloroethane (DDT). DDT, as a toxic pesticide, was included in the first batch of the 12 most hazardous and long-lasting organic compounds defined by the Stockholm Convention on Persistent Organic Pollutants (POPs) (Sharma et al., 2014; Asaoka et al., 2019). Iron-based PAO can achieve $87.9 \%$ DDT degradation, and free radicals (i.e., $\mathrm{SO}_{4}{ }^{--}$and $\mathrm{OH}^{-}$) mediate DDT degradation via stepwise hydrodechlorination, dehydrochlorination, ring-opening and final mineralization (Zhu et al., 2016b).

5) Atrazine. Atrazine is one of the most widely used pesticides in agriculture. Luo and colleagues (Luo et al., 2015) investigated atrazine degradation by using UV-based activation and oxidation of three types of oxidants (i.e., $\mathrm{H}_{2} \mathrm{O}_{2}$, peroxymonosulfate and persulfate), providing a full understanding of the role of $\mathrm{Cl}^{-}$, natural organic matter (NOM) and $\mathrm{CO}_{3}{ }^{2-} / \mathrm{HCO}_{3}{ }^{-}$on free radicals. The results showed that $\mathrm{Cl}^{-}(0.5-10 \mathrm{mmol} / \mathrm{L}), \mathrm{NOM}$ and $\mathrm{CO}_{3}{ }^{2-}$ $\mathrm{HCO}_{3}{ }^{-}$significantly scavenged free radicals. In addition, the underlying mechanism of $\mathrm{SO}_{4}{ }^{--}$-based degradation of chlorotriazine has been identified to be similar to that of $\mathrm{OH}^{-}$-based oxidation (dealkylation) (Lutze et al., 2015). The high reactivity of chloroatrizine is primarily due to the ethyl and isopropyl groups, but the dealkylated products of chlorotriazine degradation have poor reactivity to $\mathrm{SO}_{4}{ }^{-}$. Based on experiments, atrazine oxidation by free radicals has been proposed to have three transformation pathways, i.e., dealkylation, alkyl chain oxidation and dechlorinationhydroxylation (Ji et al., 2015). It is important to note that some of theproducts (e.g., di-isopropylatrazine and diethylatrazine) converted from atrazine by $\mathrm{SO}_{4}{ }^{--}$or $\mathrm{OH}$ have similar levels of toxicity to atrazine (Whalen et al., 2003).

6) Hexachlorocyclohexane $(\mathrm{HCH}) . \mathrm{HCH}$, as a pesticide includes many isomers, of which $\gamma$ - $\mathrm{HCH}$ (lindane) is the most toxic and hazardous. Experiments show that $\mathrm{Fe}^{2+}$ based PAO can altogether remove and mineralize lindane within $12 \mathrm{~h}$ (Cao et al., 2008). Further kinetic studies show that lindane degradation follows second-order degradation with a rate constant of $1.3 \times 10^{9} \mathrm{M}^{-1} \mathrm{~s}^{-1}$ (Khan et al., 2016).

7) Chloroaniline. Highly toxic and carcinogenic pchloroaniline is a critical intermediate in the synthesis of pesticides, medicines and dyes. Investigations on the PAO degradation of $\mathrm{p}$-chloroaniline showed its complete 


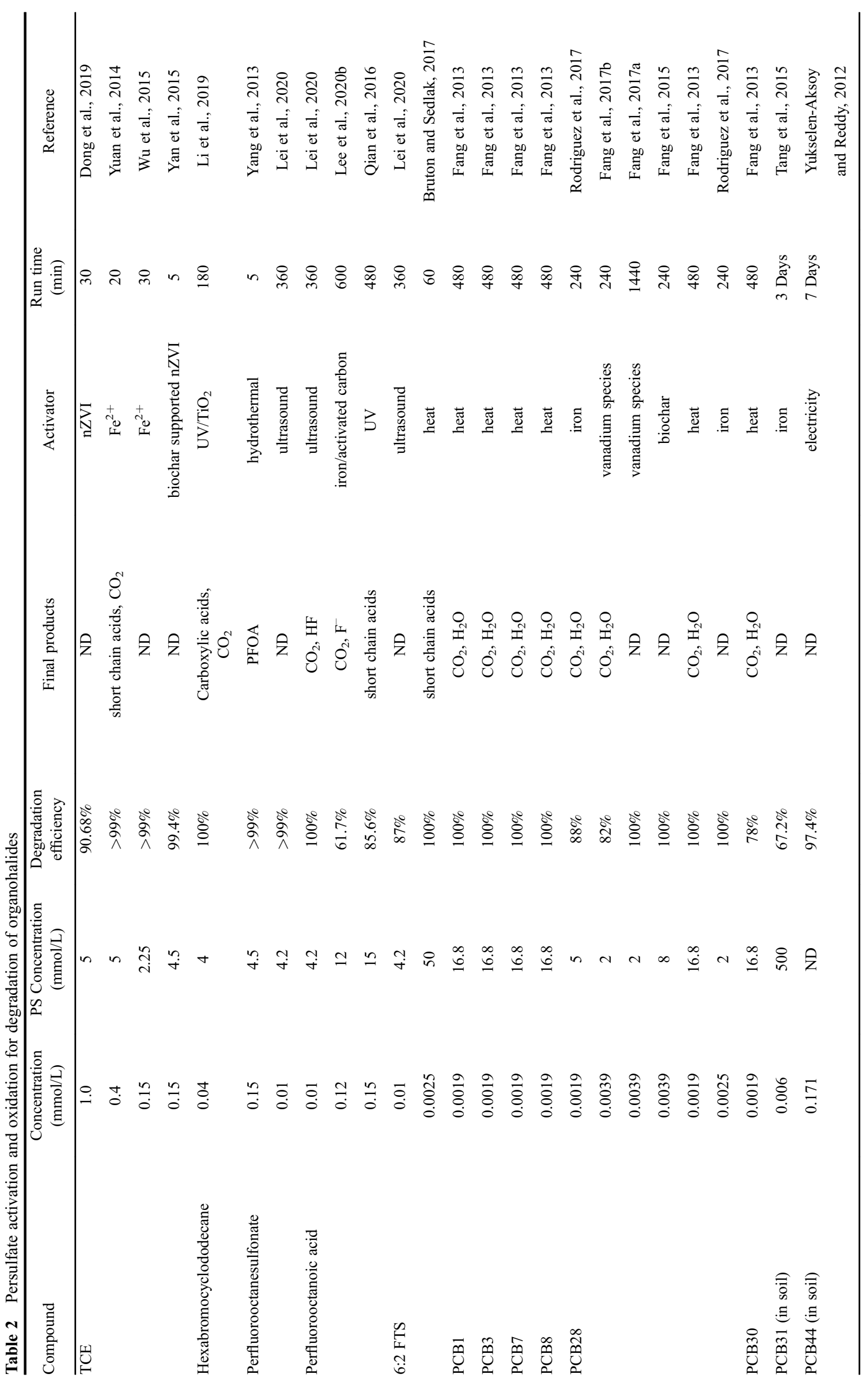




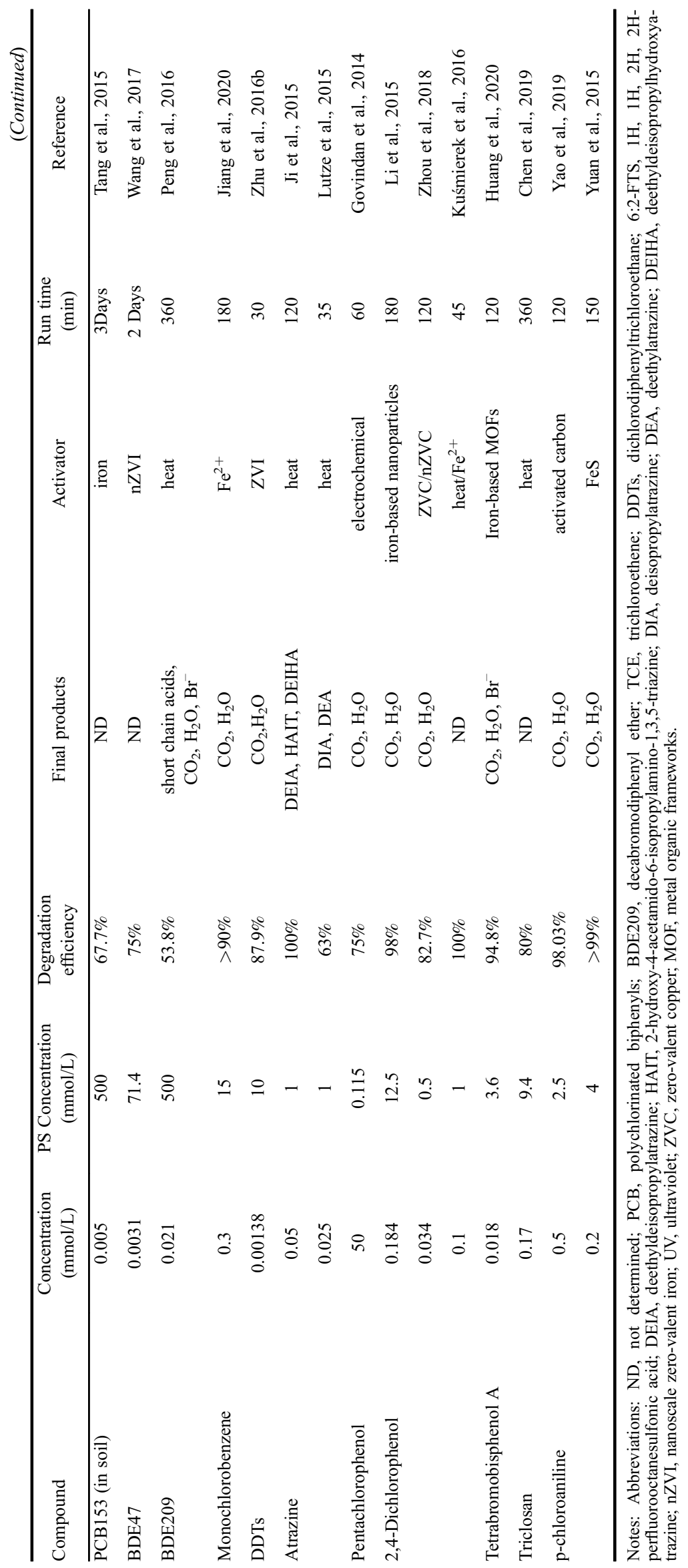


degradation and mineralization in waste streams containing p-chloroaniline (Yuan et al., 2015; Yao et al., 2019).

8) Chlorophenols. Toxic chlorophenols (e.g., pentachlorophenol or PCP) are massively produced and utilized as fungicides and antiseptics. Investigations on the degradation of $\mathrm{PCP}$ by $\mathrm{SO}_{4}^{-{ }^{-}}$and $\mathrm{OH}^{-}$radicals have shown that approximately $75 \%$ of PCP degradation and mineralization were achieved within 60 min under optimal conditions (Govindan et al., 2014). By contrast, almost complete degradation and mineralization of 2,4-dichlorophenol and tetrabromobisphenol A were achieved with PAO (Kuśmierek et al., 2016; Li et al., 2015; Zhou et al., 2018; Huang and Zhang, 2019).

Compared with the OHRB-mediated removal of highlyhalogenated organohalides, PAO is relatively more effective in the degradation and mineralization of lowlyhalogenated organohalides. Therefore, PAO may complement Bio-RD for the extensive and complete degradation and mineralization of a wide range of organohalides, particularly the highly-halogenated organohalides. Nonetheless, radicals and their intermediates play pivotal roles in PAO-based degradation of organohalides, of which radical scavenging and nonproductive reactions largely determine the overall remediation efficiency of PAO-based organohalide degradation (Crincoli et al., 2020). Consequently, future extensive studies are necessary to reveal the critical parameters affecting the reactive radicals in PAO. In addition, efforts should also go toward the prevention of hazardous byproduct formation in PAO.

\subsubsection{Advantages of PAO for organohalide degradation}

The $\mathrm{SO}_{4}{ }^{--}$-based advanced oxidation process (AOP) is a promising technology for the remediation of organohalide contamination. Compared with other AOPs, PAO has the following advantages: (1) high stability; compared with other oxidants, e.g., $\mathrm{O}_{3}$ and $\mathrm{H}_{2} \mathrm{O}_{2}$, persulfate is relatively more stable in various environmental matrices; (2) high solubility; persulfate is highly soluble and can be used for remediation of groundwater polluted by dense nonaqueous phase liquids (DNAPLs); (3) wide $\mathrm{pH}$ range; persulfate-derived $\mathrm{SO}_{4}^{-}$is less sensitive to $\mathrm{pH}$, and can mediate organohalide degradation in a wide range of $\mathrm{pH}$ conditions; (4) long lifetime; the comparatively much longer lifetime of $\mathrm{SO}_{4}{ }^{--}$relative to $\mathrm{OH}^{-}$significantly prolongs the exposure of $\mathrm{SO}_{4}{ }^{--}$to organohalides and enhances their remediation efficiency; (5) low cost and environmental impacts; PAO is a cost-effective and environmentally friendly technique for in situ remediation of organohalides.

Compared with Bio-RD, PAO has the following advantages: (1) PAO is an efficient chemical reaction process with high reactivity, which is much faster than Bio$\mathrm{RD}$; (2) persulfate-derived $\mathrm{SO}_{4}{ }^{--}$with a high redox potential of $2.5-3.1 \mathrm{~V}$ is nonselective to pollutants and can degrade a wide range of lowly-halogenated organohalides; and (3) PAO is easy to be operated and managed at remediation sites.

\subsubsection{Limitations of PAO for organohalide degradation}

Although PAO is very promising in the remediation of organohalides, there are several significant limitations in practical PAO applications:

1) Persulfate itself has very low reactivity toward organohalides, and its activation is critical for improving the degradation efficiency. Nonetheless, thermal and chemical activation methods consume much energy and chemicals, respectively (Zhang et al., 2014). The high chemical dose and energy input, as well as the long contact time (usually in days), largely hinder field applications of PAO (Zhang et al., 2014). Consequently, it is necessary to develop novel, efficient and cost-effective activation methods for PAO.

2) $\mathrm{SO}_{4}{ }^{--}$as a strong oxidant can non-selectively oxidize a wide range of organic/inorganic components, which may generate toxic byproducts (Hori et al., 2005). For example, ubiquitous chlorine ions are widespread in natural environments, and they can be oxidized to chlorine-free radicals $\left(\mathrm{Cl}_{2}{ }^{--}\right)$by $\mathrm{SO}_{4}{ }^{--}$, which not only reduces the degradation rate but also leads to the formation of harmful chlorinated products (Zhang et al., 2013). Similar problems exist for bromide as well (Fang and Shang, 2012). Consequently, preventing the generation of harmful byproducts has become a concern in applying PAO in the field remediation of organohalides.

3) The PAO process reduces the $\mathrm{pH}$ of contaminated aquifers and soil in the range of 2.8-6.0 (Liang et al., 2004; Tsitonaki et al., 2008). In addition, PAO produces a large amount of sulfate, resulting in the salinization of soil and groundwater. Therefore, improving the activation efficiency of persulfate and precisely controlling the addition amount of persulfate is of great significance in alleviating soil acidification and salinization.

4) PAO-based remediation may change the microbial community composition and function and biomass abundance at comminated sites. For example, PAO remediation was observed to result in biomass decline and a consequent decrease in organohalide biodegradation efficiency (Tsitonaki et al., 2010). To alleviate the negative impacts of PAO on microbial communities, many different biostimulation and bioaugmentation methods have been developed and employed to stimulate biodegradation activities (Sutton et al., 2011), which represent a challenge. For example, neither OHRB (e.g., Dehalococcoides) nor $r d h A$ genes have been observed after the biostimulation of the OHRB community at PAO-treated sites (Sutton et al., 2015), suggesting the disruption of natural attenuation capacities after PAO remediation. 


\section{Integration of Bio-RD and PAO (Bio-RD-PAO) for extensive attenuation of organohalides}

\subsection{Bio-RD-PAO for complete removal of organohalides}

Both anthropogenic and natural sources of organohalides result in the wide distribution of massive amounts of organohalides in different environmental matrices (Xu et al., 2006; Maucourt et al., 2020). Particularly in anoxic subsurface environments, highly-halogenated organohalides (e.g., PCBs in commercial PCB mixture Aroclor 1260) need to be reduced first before their subsequent complete degradation via oxidative processes. Consequently, an ideal bioremediation process for the in situ removal of organohalides would integrate reductive dehalogenation with subsequent oxidative degradation/ mineralization. At OHRB-based bioremediation sites, lowly-halogenated pollutants (e.g., mono- to tetra-CBs and vinyl chloride) may accumulate as intermediates await further extensive degradation. In contrast, sulfate radicals have difficulty in breaking down highly-halogenated contaminants, but they can efficiently and extensively degrade lowly-halogenated organohalides (Huang et al., 2005; Zhu et al., 2016a). Taking PCBs as an example, OHRB of different lineages have been identified to remove chlorine atoms from highly-chlorinated PCBs and generate di- to tetra-CBs, which can be effectively mineralized to $\mathrm{CO}_{2}$ and $\mathrm{H}_{2} \mathrm{O}$ by PAO (Yukselen-Aksoy and Reddy, 2012; Fang et al., 2013; Fang et al., 2017a). Therefore, integration of Bio-RD with PAO (Bio-RD-PAO) may provide a feasible process for the efficient in situ remediation of organohalides at contaminated sites.

Nonetheless, the co-existence of aggressive chemical oxidants and fastidious OHRB may have many yet-tounderstand interactions (Sutton et al., 2011; Zhang et al., 2020), hindering Bio-RD-PAO for in situ remediation applications. Previous studies have investigated the impacts of chemical oxidation as a pretreatment method to enhance both the degradability and availability of organohalides for subsequent biological conversion processes (Nam et al., 2001; Hrapovic et al., 2005; Kulik et al., 2006; Ndjou'ou et al., 2006; Sahl and Munakata-Marr, 2006; Lu et al., 2010; Venny et al., 2012; Sutton et al., 2014a). Results have shown that aggressive oxidation and deleterious effects of chemical oxidants significantly decrease the amount of biomass and change the composition of the microbial community (Sutton et al., 2014b; Němeček et al., 2019; Xia et al., 2020). Consequently, chemical pretreatments with oxidants may not improve the overall remediation efficiency. For example, the low abundance of OHRB rather than bioavailability have ultimately determined the low-rate and incomplete reaction of dehalogenation (Lombard et al., 2014). In addition, although regeneration of the microbial communities occurred after six months of chemical oxidation pretreatment, neither D. mccartyi strains as key OHRB nor any rdhA genes were observed (Sutton et al., 2015). These results suggest that consequent treatment of organohalides with Bio-RD and PAO, rather than PAO pretreatment and then Bio-RD, may be feasible to combine the strengths of Bio-RD and PAO and to prevent shortages, as well as their side effects simultaneously. In Bio-RD-PAO, various biostimulation and bioaugmentation strategies can be employed to enhance OHRB-mediated halogen removal from the highly-halogenated organohalides (Tyagi et al., 2011; Roy et al., 2018; Xu et al., 2019). For example, bioaugmentation with anaerobic microorganisms has been employed to enhance the conversion of highly-chlorinated PCBs to lowly-chlorinated PCBs. In addition, after completion of Bio-RD-PAO remediation at contamination sites, microbial communities may be regenerated by biostimulation and bioaugmentation (Dogan-Subasi et al., 2013; Martínez-Pascual et al., 2015).

\subsection{Challenges in Bio-RD-PAO for in situ remediation of organohalides}

Bio-RD-PAO may synergistically combine advantages of Bio-RD and PAO for extensive remediation of a wide range of organohalides, particularly highly-halogenated organohalides that cannot be effectively remediated by Bio-RD or PAO alone. Nonetheless, there are several major challenges for remediation applications of Bio-RDPAO:

1) Substrate addition in biostimulation may affect the subsequent PAO process. The fastidious growth requirements and long generation time of OHRB, and complicated microbial interactions result in difficulties in maintaining efficient organohalide respiration. To enhance the microbial reductive dehalogenation efficiency, many biostimulation strategies have been devised and employed, including the addition of vegetable oils as slow-releasing organic carbons and electron donors to support organohalide respiration of OHRB (Herrero et al., 2019). These biostimulation materials are left or transferred into other organic matter as intermediates, which may consume sulfate radicals and decrease the efficiency of subsequent PAO in organohalide remediation (Ouyang et al., 2017; Fang et al., 2018). In addition, a variety of minerals, ions and organic matter in soil and subsurface environments also consume persulfate-derived sulfate radicals, which has been comprehensively reviewed by Lee and colleagues (Lee et al., 2020a). The authors suggested to establish field-proven operating procedures to minimize the side impact of by-products and associated reactions on PAO (Lee et al., 2020a). Both experimental and computational evidences suggested that minerals containing iron/manganese-oxides decompose persulfate and produce active free radicals to accelerate persulfate decomposition upon contaminant's exposure (Liu et al., 2014b; Pari et al., 
2017). It is the distance between contaminants and persulfate that may affect the diffusion rate of active free radicals and the pollutant removal efficiency. Therefore, the effects of biostimulation substrates-derived matter on subsequent PAO are different under varied environmental conditions, on which the detailed information remain elusive.

2) Mechanisms underlying the oxidative PAO process in aerobic and anaerobic environments may be different from each other, which remain elusive. Persulfate activation is generally performed under aerobic conditions, and there are limited reports of persulfate activation in anaerobic environments. Recently, both reductive dechlorination and consequent oxidation of hexachloroethane were observed during the PAO process under anaerobic conditions ( $\mathrm{Zhu}$ et al., 2018b), in which persulfate radicals $\left(\mathrm{S}_{2} \mathrm{O}_{8}{ }^{-}\right)$were identified to play a significant role in hexachloroethane degradation. Interestingly, in another study on PAO under anaerobic conditions, persulfate-derived alcohol radicals (ARs) with low redox potential were proposed to reductively dechlorinate trichloroacetic acid (TCA) and carbon tetrachloride $\left(\mathrm{CCl}_{4}\right)$ ( $\mathrm{Zhu}$ et al., 2018a). Other oxidative radicals (e.g., $\mathrm{SO}_{4}{ }^{-}$and $\mathrm{OH}^{-}$) were generated in the subsequent radical chain reactions, which further reacted with lowly-chlorinated intermediates and converted them into $\mathrm{CO}_{2}$ and chloride ions (Zhu et al., 2018a; $\mathrm{Zhu}$ et al., 2018b). Therefore, under anaerobic conditions, persulfate can be activated to generate both reductive radicals and oxidative radicals through radical chain reactions, which warrants more experimental and mechanistic investigations.

3) A third challenge is that of the effective integration of Bio-RD and PAO for complete degradation of organohalides. Theoretically, Bio-RD can remove halogens from highly-halogenated organohalides, and then PAO can effectively and extensively degrade the dehalogenation products. Nonetheless, during Bio-RD, various parameters work together to determine the number of removed chlorine compounds, particularly the OHRB and their growth conditions, resulting in the varied extent of dehalogenation (Nijenhuis and Kuntze, 2016; Wang et al., 2018). For example, recently isolated and characterized D. mccartyi CG1 and CG5 could dechlorinate PCB180 (2345-245-CB) to hexa-CB (245-245-CB) and tetra-CB (24-24-CB), respectively (Wang et al., 2014). Subsequent PAO-based degradation of the generated hexa- and tetra$\mathrm{CBs}$ has different efficiencies, and $\mathrm{PAO}$ is more effective in degrading the lowly-chlorinated PCBs (Rybnikova et al., 2016).

4) The hydrophobic properties of organohalides severely restrict their bioavailability and in situ chemical oxidation efficiencies. The hydrophobicity of organohalides results in their low availability, which leads to the low and incomplete degradation of organohalides by Bio-RD-PAO. Particularly in organohalide-contaminated subsurface environments, the organohalides may be adsorbed to soil organic matter. To enhance the desorption and dissolution of organohalides, soil heating strategies were investigated to improve microbial reductive dehalogenation and subsequent activation of persulfate (Peng et al., 2016). The heating temperature is a critical parameter, and high temperature may inactivate the OHRB and result in persulfate decomposition. Nonetheless, soil heating is an energy-intensive process. Recent studies showed that biostimulation with nutrients and surfactants promoted cell growth of OHRB by increasing the bioavailability of hydrophobic organohalides (Jasmine and Mukherji, 2014), which may be a feasible way to enhance the efficiency of Bio-RD-PAO in organohalide remediation.

5) The integrated Bio-RD-PAO process may affect the abundance of biomass, microbial community composition and physiochemical properties of remediated soil by increasing redox potential and decreasing $\mathrm{pH}$ (Sutton et al., 2014b; Sutton et al., 2015). Although the regeneration of microbial communities can be achieved through biostimulation and bioaugmentation, unpredictable side effects may occur at remediation sites (Sutton et al., 2011; Cycoń et al., 2017). For example, microbial activities have been changed even after microbial community regeneration (Sutton et al., 2015). Therefore, it is challenging to alleviate the side impacts of persulfate oxidation on microbial communities and their activities. Although it has been reported that the impacts of persulfate activation oxidation on bioremediation are reduced by optimizing the molar ratio of persulfate and pollutants, as well as of persulfate and activators (Xia et al., 2020), the specific mechanism is still unclear.

\section{Conclusions and future perspectives}

Bio-RD and PAO are two efficient techniques for in situ remediation of highly-halogenated and lowly-halogenated organohalides, respectively. Bio-RD-PAO via sequential integration of Bio-RD and $\mathrm{PAO}$ can provide a solution for remediation of a wide range of organohalides, which is not only feasible but extensive, efficient and cost-effective, if properly implemented, compared with Bio-RD and PAO treatment alone. To enhance the efficiency of Bio-RD-PAO in remediation of organohalide pollution, the following perspectives are proposed for future studies:

1) Novel surfactants should be developed to improve the availability of hydrophobic organohalides for Bio-RDPAO. Hydrophobic organohalides may bond to soil organic matter, which severely decreases their availability and results in low dechlorination efficiency. Surfactants can enhance the organohalide removal by improving the organohalides' bioavailability and the interaction between cell surface and reactants (Mulligan and Gibbs, 2004; Liu et al., 2021). A variety of surfactants (e.g., anionic, cationic, zwitterionic and nonionic surfactants) have been developed and applied in soil remediation (Fountain et al., 
1996; Mao et al., 2015), including bioremediation (PacwaPlociniczak et al., 2011), phytoremediation (Aioub et al., 2019) and electrokinetic remediation (Fardin et al., 2021; Chen et al., 2021). To develop novel surfactants for enhanced remediation of organohalide-contaminated soil, especially for the Bio-RD-PAO process, the following properties of the surfactants should be considered:

(a) The surfactants cannot inhibit the microbial activity. Although surfactant-amended bioremediation has been widely applied, the impact of surfactants on the organohalide degradation have been controversial in the past years, and little is known about the effect of emulsifiers on the biodegradation of complex hydrocarbon mixtures. To clarify the effect of surfactant addition on microbial activity and pollutant removal efficiency, Liu et al. (2016) compared the effects of three surfactants (Tween80, TritonX-100 and Brij30) and found that Tween 80 promoted the growth and activity of microorganisms (Sphingomonas sp. GY2B), and improved the pollutant degradation efficiency. By contrast, slight and severe inhibitions were observed in cultures amended with TritonX-100 and Brij30, respectively (Liu et al., 2016).

(b) There is a good compatibility of surfactants with the microorganisms and oxidants. Several studies testing the chemical compatibility between surfactants and pollutants suggested that alcohol-based surfactants were more likely to react with pollutants and not conducive to use with the oxidants (Zhai et al., 2006).

(c) The surfactants should not quench the persulfatederived free radicals. Previous studies showed that removal of organohalides were improved by combining nonionic surfactants (e.g., TX-100, Brij-35 and E-Mulse $3 \circledR$ ) and oxidants (Mulligan and Eftekhari, 2003; Villa et al., 2010; Rios et al., 2013; Dominguez et al., 2019). Interestingly, a recent study comparing the effect of three nonionic surfactants (E-Mulse 3®), Tween 80 and a mixture of Tween80-Span80) and an anion surfactant (sodium dodecyl sulfate, SDS) on PAO degradation of organohalides demonstrated that combining SDS and Emulse-3 ${ }^{\circledR}$ consumed less persulfate, but was more efficient, relative to SDS (García-Cervilla et al., 2021).

Therefore, interactions among surfactants, oxidants and organohalides are complicated, and the selection of optimum surfactants for ISCO treatment is challenging. The compatibility of surfactants with oxidants, the solubility of surfactants, and the oxidation rate of organohalides in aqueous surfactant emulsion warrant future investigation.

2) Multifunctional materials and techniques can be devised for simultaneous stimulation of Bio-RD and persulfate activation. For example, glucose was recently utilized to activate persulfate and, at the same time, provide a carbon source for indigenous microorganisms, which work together to effectively degrade nitrobenzene and chloroethane (Watts et al., 2018). Moreover, surfactant foam could be an effective carrier for OHRB and persulfate in the vadose zone, which has been successfully employed to enhance remediation of contaminated soil (Zhang et al., 2012; Bajagain et al., 2018; Bouzid et al., 2019; Bajagain et al., 2020). Consequently, new materials with multiple similar functions should be developed specifically to enhance the organohalide remediation efficiency of BioRD-PAO.

3) Strategies should be developed to alleviate the side effects of Bio-RD and PAO, which include capsulation of OHRB and their growth-requiring nutrients and substrates for Bio-RD-PAO-based in situ remediation. The OHRBdwelling and nutrient-slow-releasing capsules can alleviate the strong-oxidative damaging effects of PAO on the OHRB by preventing direct contact of the OHRB with persulfate-derived oxidative species. Many other novel materials have been developed to protect anaerobic bacteria from exposure to oxygen and other oxidative species. For example, Ji and colleagues (Ji et al., 2018) recently developed a cytoprotective metal-organic frameworks (MOFs) material to wrap anaerobes and to decompose reactive oxygen species, which decreased anaerobic cell damage by 5 -fold upon oxygen exposure.

4) To completely mineralize highly-halogenated organohalides, it is crucial that the OHRB can effectively remove halogens from highly-halogenated substrates. For a specific organohalide pollutant, the proper organohaliderespiring bacterial candidate may be different. Of the currently-characterized OHRB, Dehalococcoides represents a unique lineage for reductive dechlorination of a wide range of organohalides, and is an optimal candidate for applying the Bio-RD-PAO process. For example, Dehalococcoides is one of the only two organohaliderespiring genera able to dechlorinate hexachlorocyclohexane (HCH) (Doesburg et al., 2005; Maphosa et al., 2012; Bashir et al., 2018). Dehalococcoides transforms ( $\alpha, \beta, \gamma$, $\delta)-\mathrm{HCH}$ to monochlorobenzene and benzene (Bashir et al., 2018), which enables their efficient and complete degradation via subsequent PAO. For reductive dichlorination of PCBs, Dehalococcoides, Dehalogenimonas and Dehalobacter can remove flanked meta-/para-chlorines from PCBs with different specificities and generate a variety of lowly-chlorinated PCBs for subsequent degradation using PAO. Therefore, the overall efficiency of degrading PCBs and other organohalides in the Bio-RD-PAO process may be optimized by screening and selection of proper OHRB based on extensive cultivation studies.

5) For the complete degradation of highly-halogenated organohalides, dehalogenation products of Bio-RD may be further degraded by aerobic microorganisms (Rieger et al., 2002), which has been observed in natural environments for attenuation of organohalide pollutants (Abramowicz, 1995). The stepwise anaerobic-aerobic coupled process has been employed for the removal of a variety of organohalides, including chloroethenes (Yoshikawa et al., 2017), HCB (Kengara et al., 2013), TBBPA (Ronen and Abeliovich, 2000), PCBs (Tsuneta et al., 2008; Pathiraja 
et al., 2019), and PBDEs (Pan et al., 2019). For example, approximately $70 \%$ of Aroclors can be effectively degraded by coupling an anaerobic PCB-dechlorinating culture with an aerobic culture containing Burkholderia xenovorans LB400 (Evans et al., 1996; Master et al., 2002). Nonetheless, compared with Bio-RD-PAO, the sequential anaerobic-aerobic coupled process may have disadvantages, including a long remediation time (Liu et al., 2013) and high substrate selectivity (Sowers and May, 2013). For example, PCB dechlorinating products with ortho-chlorines are recalcitrant to aerobic degradation, but can be easily degraded by PAO. Compared with the sequential anaerobic-aerobic coupled process and the detailed pros and cons, as well as how to prevent its drawbacks, in-depth studies are needed to further investigate Bio-RD-PAO.

Acknowledgements This study was supported by the National Natural Science Foundation of China (Grant Nos. 41922049 and 41877111), the Fundamental Research Funds for the Central Universities (No. 19lgzd30) and the Guangzhou Science and Technology Program general project (No. 201804010141).

Open Access This article is licensed under a Creative Commons Attribution 4.0 International License, which permits use, sharing, adaptation, distribution and reproduction in any medium or format, as long as you give appropriate credit to the original author(s) and the source, provide a link to the Creative Commons licence, and indicate if changes were made. The images or other third party material in this article are included in the article's Creative Commons licence, unless indicated otherwise in a credit line to the material. If material is not included in the article's Creative Commons licence and your intended use is not permitted by statutory regulation or exceeds the permitted use, you will need to obtain permission directly from the copyright holder. To view a copy of this licence, visit http://creativecommons.org/licenses/by/4.0/.

\section{References}

Abramowicz D A (1995). Aerobic and anaerobic PCB biodegradation in the environment. Environmental Health Perspectives, 103: 97-99

Adrian L, Dudkova V, Demnerova K, Bedard D L (2009). “Dehalococcoides" sp. strain CBDB1 extensively dechlorinates the commercial polychlorinated biphenyl mixture aroclor 1260. Applied and Environmental Microbiology, 75(13): 4516-4524

Adrian L, Löffler F E (2016). Organohalide-respiring bacteria. Heidelberg: Springer-Verlag

Ahmad M, Teel A L, Watts R J (2010). Persulfate activation by subsurface minerals. Journal of Contaminant Hydrology, 115(1-4): 34-45

Ahmad M, Teel A L, Watts R J (2013). Mechanism of persulfate activation by phenols. Environmental Science \& Technology, 47(11): 5864-5871

Aioub A A A, Li Y, Qie X, Zhang X, Hu Z (2019). Reduction of soil contamination by cypermethrin residues using phytoremediation with Plantago major and some surfactants. Environmental Sciences Europe, 31(1): 26

Anipsitakis G P, Dionysiou D D (2004). Radical generation by the interaction of transition metals with common oxidants. Environ- mental Science \& Technology, 38(13): 3705-3712

Antoniou K, Mamais D, Pantazidou D (2019). Reductive dechlorination of trichloroethene under different sulfate-reducing and electron donor conditions. Journal of Contaminant Hydrology, 226: 103519

Asaoka S, Umehara A, Haga Y, Matsumura C, Yoshiki R, Takeda K (2019). Persistent organic pollutants are still present in surface marine sediments from the Seto Inland Sea, Japan. Marine Pollution Bulletin, 149: 110543

Atashgahi S, Liebensteiner M G, Janssen D B, Smidt H, Stams A J M, Sipkema D (2018). Microbial synthesis and transformation of inorganic and organic chlorine compounds. Frontiers in Microbiology, 9: 1-22

Aulenta F, Pera A, Rossetti S, Petrangeli Papini M, Majone M (2007). Relevance of side reactions in anaerobic reductive dechlorination microcosms amended with different electron donors. Water Research, 41(1): 27-38

Bajagain R, Gautam P, Jeong S W (2020). Degradation of petroleum hydrocarbons in unsaturated soil and effects on subsequent biodegradation by potassium permanganate. Environmental Geochemistry and Health, 42(6): 1705-1714

Bajagain R, Lee S, Jeong S W (2018). Application of persulfateoxidation foam spraying as a bioremediation pretreatment for diesel oil-contaminated soil. Chemosphere, 207: 565-572

Bashir S, Kuntze K, Vogt C, Nijenhuis I (2018). Anaerobic biotransformation of hexachlorocyclohexane isomers by Dehalococcoides species and an enrichment culture. Biodegradation, 29(4): 409-418

Bedard D L (2008). A case study for microbial biodegradation: anaerobic bacterial reductive dechlorination of polychlorinated biphenyls-from sediment to defined medium. Annual Review of Microbiology, 62(1): 253-270

Behrman E J (2006). The Elbs and Boyland-Sims peroxydisulfate oxidations. Beilstein Journal of Organic Chemistry, 2: 22

Berggren D R V, Marshall I P G, Azizian M F, Spormann A M, Semprini L (2013). Effects of sulfate reduction on the bacterial community and kinetic parameters of a dechlorinating culture under chemostat growth conditions. Environmental Science \& Technology, 47(4): 1879-1886

Bisaillon A, Beaudet R, Lepine F, Deziel E, Villemur R (2010). Identification and characterization of a novel CprA reductive dehalogenase specific to highly chlorinated phenols from Desulfitobacterium hafniense strain PCP-1. Applied and Environmental Microbiology, 76(22): 7536-7540

Bokare A D, Choi W (2014). Review of iron-free Fenton-like systems for activating $\mathrm{H}_{2} \mathrm{O}_{2}$ in advanced oxidation processes. Journal of Hazardous Materials, 275: 121-135

Bommer M, Kunze C, Fesseler J, Schubert T, Diekert G, Dobbek H (2014). Structural basis for organohalide respiration. Science, 346 (6208): 455-458

Bouzid I, Maire J, Fatin-Rouge N (2019). Comparative assessment of a foam-based oxidative treatment of hydrocarbon-contaminated unsaturated and anisotropic soils. Chemosphere, 233: 667-676

Bruton T A, Sedlak D L (2017). Treatment of aqueous film-forming foam by heat-activated persulfate under conditions representative of in situ chemical oxidation. Environmental Science \& Technology, 51 (23): $13878-13885$ 
Bunge M, Adrian L, Kraus A, Opel M, Lorenz W G, Andreesen J R, Görisch H, Lechner U (2003). Reductive dehalogenation of chlorinated dioxins by an anaerobic bacterium. Nature, 421(6921): $357-360$

Cai Z, Zhao X, Duan J, Zhao D, Dang Z, Lin Z (2020). Remediation of soil and groundwater contaminated with organic chemicals using stabilized nanoparticles: Lessons from the past two decades. Frontiers of Environmental Science \& Engineering, 14(5): 84

Cao J, Zhang W X, Brown D G, Sethi D (2008). Oxidation of Lindane with Fe(II)-Activated Sodium Persulfate. Environmental Engineering Science, 25(2): 221-228

Cervantes-González E, Guevara-García M A, García-Mena J, OvandoMedina V M (2019). Microbial diversity assessment of polychlorinated biphenyl-contaminated soils and the biostimulation and bioaugmentation processes. Environmental Monitoring and Assessment, 191(2): 118

Chen C, He J (2018). Strategy for the rapid dechlorination of polychlorinated biphenyls (PCBs) by Dehalococcoides mccartyi strains. Environmental Science \& Technology, 52(23): 13854-13862

Chen F, Zhang Q, Ma J, Zhu Q, Wang Y, Liang H (2021). Effective remediation of organic-metal co-contaminated soil by enhanced electrokinetic-bioremediation process. Frontiers of Environmental Science \& Engineering, 15(6): 113

Chen L, Hu X, Cai T, Yang Y, Zhao R, Liu C, Li A, Jiang C (2019). Degradation of triclosan in soils by thermally activated persulfate under conditions representative of in situ chemical oxidation (ISCO). Chemical Engineering Journal, 369: 344-352

Crincoli K R, Green C, Huling S G (2020). Sulfate Radical Scavenging by Mineral Surfaces in Persulfate-Driven Oxidation Systems: Reaction Rate Constants and Implications. Environmental Science \& Technology, 54(3): 1955-1962

Cutter L A, Watts J E M, Sowers K R, May H D (2001). Identification of a microorganism that links its growth to the reductive dechlorination of 2,3,5,6-chlorobiphenyl. Environmental Microbiology, 3(11): 699709

Cycoń M, Mrozik A, Piotrowska-Seget Z (2017). Bioaugmentation as a strategy for the remediation of pesticide-polluted soil: A review. Chemosphere, 172: 52-71

Dam H T, Sun W, Mcguinness L, Kerkhof L J, Haggblom M M (2019). Identification of a Chlorodibenzo-p-dioxin dechlorinating Dehalococcoides mccartyi by stable isotope probing. Environmental Science \& Technology, 53(24): 14409-14419

Dam H T, Vollmers J, Kaster A K, Häggblom M M (2017). Reconstructed genomes of novel Dehalococcoides mccartyi strains from 1,2,3,4-tetrachlorodibenzo-p-dioxin-dechlorinating enrichment cultures reveal divergent reductive dehalogenase gene profiles. FEMS Microbiology Ecology, 93(12): fix151

Dean R K, Schneider C R, Almnehlawi H S, Dawson K S, Fennell D E (2020). 2,3,7,8-Tetrachlorodibenzo-p-dioxin dechlorination is differentially enhanced by dichlorobenzene amendment in Passaic River, NJ Sediments. Environmental Science \& Technology, 54(13): 8380 8389

Desforges J, Hall A, Mcconnell B, Rosing-Asvid A, Barber J L, Brownlow A, De Guise S, Eulaers I, Jepson P D, Letcher R J, Levin M, Ross P S, Samarra F, Víkingson G, Sonne C, Dietz R (2018). Predicting global killer whale population collapse from PCB pollution. Science, 361(6409): 1373-1376

Devi P, Das U, Dalai A K (2016). In-situ chemical oxidation: Principle and applications of peroxide and persulfate treatments in wastewater systems. Science of the Total Environment, 571: 643-657

DeWeerd K, Mandelco L, Tanner R, Woese C J S, Suflita J M (1990). Desulfomonile tiedjei gen. nov. and sp. nov., a novel anaerobic, dehalogenating, sulfate-reducing bacterium. Archives of Microbiology, 154(1): 23-30

Ding C, Rogers M J, Yang K L, He J (2017). Loss of the ssrA genome island led to partial debromination in the PBDE respiring Dehalococcoides mccartyi strain GY50. Environmental Microbiology, 19(7): 2906-2915

Doesburg W, Eekert M H A, Middeldorp P J M, Balk M, Schraa G, Stams A J M (2005). Reductive dechlorination of $\beta$-hexachlorocyclohexane $(\beta-\mathrm{HCH})$ by a Dehalobacter species in coculture with a Sedimentibacter sp. FEMS Microbiology Ecology, 54(1): 87-95

Doğan-Subasi E, Bastiaens L, Boon N, Dejonghe W (2013). Microbial dechlorination activity during and after chemical oxidant treatment. Journal of Hazardous Materials, 262: 598-605

Dominguez C M, Romero M, Santos A (2019). Selective removal of chlorinated organic compounds from lindane wastes by combination of nonionic surfactant soil flushing and Fenton oxidation. Chemical Engineering Journal, 376: 120009

Dong H, Hou K, Qiao W, Cheng Y, Zhang L, Wang B, Li L, Wang Y, Ning Q, Zeng G (2019). Insights into enhanced removal of TCE utilizing sulfide-modified nanoscale zero-valent iron activated persulfate. Chemical Engineering Journal, 359: 1046-1055

Duan X, Sun H, Shao Z, Wang S (2018). Nonradical reactions in environmental remediation processes: Uncertainty and challenges. Applied Catalysis B: Environmental, 224: 973-982

Evans B S, Dudley C A, Klasson K T (1996). Sequential anaerobicaerobic biodegradation of $\mathrm{PCBs}$ in soil slurry microcosms. Applied Biochemistry and Biotechnology, 57-58(1): 885-894

Fang G, Chen X, Wu W, Liu C, Dionysiou D D, Fan T, Wang Y, Zhu C, Zhou D (2018). Mechanisms of interaction between persulfate and soil constituents: Activation, free radical formation, conversion, and identification. Environmental Science \& Technology, 52(24): 1435214361

Fang G, Liu C, Gao J, Dionysiou D D, Zhou D (2015). Manipulation of persistent free radicals in biochar to activate persulfate for contaminant degradation. Environmental Science \& Technology, 49 (9): 5645-5653

Fang G, Wu W, Deng Y, Zhou D (2017a). Homogenous activation of persulfate by different species of vanadium ions for PCBs degradation. Chemical Engineering Journal, 323: 84-95

Fang G, Wu W, Liu C, Dionysiou D D, Deng Y, Zhou D (2017b). Activation of persulfate with vanadium species for PCBs degradation: A mechanistic study. Applied Catalysis B: Environmental, 202: $1-11$

Fang G D, Dionysiou D D, Zhou D M, Wang Y, Zhu X D, Fan J X, Cang L, Wang Y J (2013). Transformation of polychlorinated biphenyls by persulfate at ambient temperature. Chemosphere, 90(5): 1573-1580

Fang J Y, Shang C (2012). Bromate formation from bromide oxidation by the UV/persulfate process. Environmental Science \& Technology, 46(16): 8976-8983

Fardin A B, Jamshidi-Zanjani A, Darban A K (2021). Application of 
enhanced electrokinetic remediation by coupling surfactants for kerosene-contaminated soils: Effect of ionic and nonionic surfactants. Journal of Environmental Management, 277: 111422

Fennell D E, Nijenhuis I, Wilson S F, Zinder S H, Häggblom M M (2004). Dehalococcoides ethenogenes strain 195 reductively dechlorinates diverse chlorinated aromatic pollutants. Environmental Science \& Technology, 38(7): 2075-2081

Fiedler H (2007). National PCDD/PCDF release inventories under the Stockholm Convention on persistent organic pollutants. Chemosphere, 67(9): S96-S108

Fincker M, Spormann A M (2017). Biochemistry of Catabolic Reductive Dehalogenation. Annual Review of Biochemistry, 86(1): 357-386

Fountain J C, Starr R C, Middleton T, Beikirch M, Taylor C, Hodge D (1996). A controlled field test of surfactant-enhanced aquifer remediation. Ground Water, 34(5): 910-916

Fricker A D, LaRoe S L, Shea M E, Bedard D L (2014). Dehalococcoides mccartyi strain JNA dechlorinates multiple chlorinated phenols including pentachlorophenol and harbors at least 19 reductive dehalogenase homologous genes. Environmental Science \& Technology, 48(24): 14300-14308

García-Cervilla R, Santos A, Romero A, Lorenzo D (2021). Compatibility of nonionic and anionic surfactants with persulfate activated by alkali in the abatement of chlorinated organic compounds in aqueous phase. Science of the Total Environment, 751: 141782

Govindan K, Raja M, Noel M, James E J (2014). Degradation of pentachlorophenol by hydroxyl radicals and sulfate radicals using electrochemical activation of peroxomonosulfate, peroxodisulfate and hydrogen peroxide. Journal of Hazardous Materials, 272: 42-51

Gushgari-Doyle S, Alvarez-Cohen L (2020). Effects of Arsenic on Trichloroethene-Dechlorination Activities of Dehalococcoides mccartyi 195. Environmental Science \& Technology, 54(2): 12761285

Heavner G L W, Mansfeldt C B, Wilkins M J, Nicora C D, Debs G E, Edwards E A, Richardson R E (2019). Detection of organohaliderespiring enzyme biomarkers at a bioaugmented TCE-contaminated field site. Frontiers in Microbiology, 10: 1433

Heckel B, Phillips E, Edwards E, Sherwood Lollar B, Elsner M, Manefield M J, Lee M (2019). Reductive dehalogenation of trichloromethane by two different Dehalobacterrestrictus strains reveal opposing dual element isotope effects. Environmental Science \& Technology, 53(5): 2332-2343

Heimann A C , FriisA K, Jakobsen R (2005). Effects of sulfate on anaerobic chloroethene degradation by an enriched culture under transient and steady-state hydrogen supply. Water Research, 39(15): 3579-3586

Herrero J, Puigserver D, Nijenhuis I, Kuntze K, Carmona J M (2019). Combined use of ISCR and biostimulation techniques in incomplete processes of reductive dehalogenation of chlorinated solvents. Science of the Total Environment, 648: 819-829

Hori H, Yamamoto A, Hayakawa E, Taniyasu S, Yamashita N, Kutsuna S, Kiatagawa H, Arakawa R (2005). Efficient decomposition of environmentally persistent perfluorocarboxylic acids by use of persulfate as a photochemical oxidant. Environmental Science \& Technology, 39(7): 2383-2388

Hrapovic L, Sleep B E, Major D J, Hood E D (2005). Laboratory study of treatment of trichloroethene by chemical oxidation followed by bioremediation. Environmental Science \& Technology, 39(8): 28882897

Huang A, Zhang Z, Wang N, Zhu L, Zou J (2016). Green mechanochemical oxidative decomposition of powdery decabromodiphenyl ether with persulfate. Journal of Hazardous Materials, 302 : $158-165$

Huang J, Zhang H (2019). Mn-based catalysts for sulfate radical-based advanced oxidation processes: A review. Environment International, 133: 105141

Huang K C, Zhao Z, Hoag G E, Dahmani A, Block P A (2005). Degradation of volatile organic compounds with thermally activated persulfate oxidation. Chemosphere, 61(4): 551-560

Huang M, Wang Y, Wan J, Ma Y, Chi H, Xu Y, Qiu S (2020). Facile construction of highly reactive and stable defective iron-based metal organic frameworks for efficient degradation of Tetrabromobisphenol A via persulfate activation. Environmental Pollution, 256: 113399

Huang K C, Couttenye R A, Hoag G E (2002). Kinetics of heat-assisted persulfate oxidation of methyl tert-butyl ether (MTBE). Chemosphere 49: 413-420

Hug L A, Maphosa F, Leys D, Löffler F E, Smidt H, Edwards E A, Adrian L (2013). Overview of organohalide-respiring bacteria and a proposal for a classification system for reductive dehalogenases. Philosophical Transactions of the Royal Society of London. Series B, Biological Sciences, 368(1616): 20120322

Ike I A, Linden K G, Orbell J D, Duke M (2018). Critical review of the science and sustainability of persulphate advanced oxidation processes. Chemical Engineering Journal, 338: 651-669

Jasmine J, Mukherji S (2014). Evaluation of bioaugmentation and biostimulation effects on the treatment of refinery oily sludge using 2 (n) full factorial design. Environmental Science. Processes \& Impacts, 16(8): 1889-1896

Ji Y, Dong C, Kong D, Lu J, Zhou Q (2015). Heat-activated persulfate oxidation of atrazine: Implications for remediation of groundwater contaminated by herbicides. Chemical Engineering Journal, 263: 4554

Ji Z, Zhang H, Liu H, Yaghi O M, Yang P (2018). Cytoprotective metalorganic frameworks for anaerobic bacteria. Proceedings of the National Academy of Sciences of the United States of America, 115 (42): 10582-10587

Jiang F, Li Y, Zhou W, Yang Z, Ning Y, Liu D, Tang Z, Yang S, Huang $H$, Wang G (2020). Enhanced degradation of monochlorobenzene in groundwater by ferrous iron/persulfate process with cysteine. Chemical Engineering Journal, 387: 124048

Johnson-Restrepo B, Kannan K, Addink R, Adams D H (2005). Polybrominated diphenyl ethers and polychlorinated biphenyls in a marine foodweb of coastal Florida. Environmental Science \& Technology, 39(21): 8243-8250

Jugder B E, Ertan H, Bohl S, Lee M, Marquis C P, Manefield M (2016). Organohalide respiring bacteria and reductive dehalogenases: Key tools in organohalide bioremediation. Frontiers in Microbiology, 7: 249

Jugder B E, Ertan H, Lee M, Manefield M, Marquis C P (2015). Reductive dehalogenases come of age in biological destruction of organohalides. Trends in Biotechnology, 33(10): 595-610

Karim A V, Jiao Y, Zhou M, Nidheesh P V (2021). Iron-based persulfate activation process for environmental decontamination in water and 
soil. Chemosphere, 265: 129057

Kaya D, Kjellerup B V, Chourey K, Hettich R L, Taggart D M, Löffler F E (2019). Impact of fixed nitrogen availability on Dehalococcoides mccartyi reductive dechlorination activity. Environmental Science \& Technology, 53(24): 14548-14558

Kengara F O, Doerfler U, Welzl G, Ruth B, Munch J C, Schroll R (2013). Enhanced degradation of C-14-HCB in two tropical clay soils using multiple anaerobic-aerobic cycles. Environmental Pollution, 173: $168-175$

Key T A, Bowman K S, Lee I, Chun J, Albuquerque L, Da Costa M S, Rainey F A, Moe W M (2017). Dehalogenimonas formicexedens sp. nov., a chlorinated alkane-respiring bacterium isolated from contaminated groundwater. International Journal of Systematic and Evolutionary Microbiology, 67(5): 1366-1373

Khan S, He X, Khan H M, Boccelli D, Dionysiou D D (2016). Efficient degradation of lindane in aqueous solution by iron (II) and/or UV activated peroxymonosulfate. Journal of Photochemistry and Photobiology A Chemistry, 316: 37-43

Kublik A, Deobald D, Hartwig S, Schiffmann C L, Andrades A, Von Bergen M, Sawers R G, Adrian L (2016). Identification of a multiprotein reductive dehalogenase complex in Dehalococcoides mccartyi strain CBDB1 suggests a protein-dependent respiratory electron transport chain obviating quinone involvement. Environmental Microbiology, 18(9): 3044-3056

Kulik N, Goi A, Trapido M, Tuhkanen T (2006). Degradation of polycyclic aromatic hydrocarbons by combined chemical preoxidation and bioremediation in creosote contaminated soil. Journal of Environmental Management, 78(4): 382-391

Kunze C, Bommer M, Hagen W R, Uksa M, Dobbek H, Schubert T, Diekert $\mathrm{G}$ (2017). Cobamide-mediated enzymatic reductive dehalogenation via long-range electron transfer. Nature Communications, 8 (1): 15858

Kuśmierek K, Dąbek L, Świątkowski A (2016). A comparative study on oxidative degradation of 2,4-dichlorophenol and 2,4-dichlorophenoxyacetic acid by ammonium persulfate. Desalination and Water Treatment, 57(3): 1098-1106

LaRoe S L, Fricker A D, Bedard D L (2014). Dehalococcoides mccartyi strain JNA in pure culture extensively dechlorinates Aroclor 1260 according to polychlorinated biphenyl (PCB) dechlorination Process N. Environmental Science \& Technology, 48(16): 9187-9196

Lee J, Im J, Kim U, Löffler F E (2016). A Data Mining Approach to Predict In Situ Detoxification Potential of Chlorinated Ethenes. Environmental Science \& Technology, 50(10): 5181-5188

Lee J, Von Gunten U, Kim J H (2020a). Persulfate-based advanced oxidation: Critical assessment of opportunities and roadblocks. Environmental Science \& Technology, 54(6): 3064-3081

Lee Y C, Li Y F, Chen M J, Chen Y C, Kuo J, Lo S L (2020b). Efficient decomposition of perfluorooctanic acid by persulfate with ironmodified activated carbon. Water Research, 174: 115618

Lei Y J, Tian Y, Sobhani Z, Naidu R, Fang C (2020). Synergistic degradation of PFAS in water and soil by dual-frequency ultrasonic activated persulfate. Chemical Engineering Journal, 388: 124215

Li K, Li H, Xiao T, Zhang G, Liang A, Zhang P, Lin L, Chen Z, Cao X, Long J (2020). Zero-valent manganese nanoparticles coupled with different strong oxidants for thallium removal from wastewater. Frontiers of Environmental Science \& Engineering, 14(2): 34
Li Q, Wang L, Fang X, Zhang L, Li J, Xie H (2019). Synergistic effect of photocatalytic degradation of hexabromocyclododecane in water by $\mathrm{UV} / \mathrm{TiO}_{2}$ /persulfate. Catalysts, 9(2): 189

Li R, Jin X, Megharaj M, Naidu R, Chen Z (2015). Heterogeneous Fenton oxidation of 2,4-dichlorophenol using iron-based nanoparticles and persulfate system. Chemical Engineering Journal, 264: 587594

Li T, Zhang C, Zhang J, Yan S, Qin C (2021). Remediation of 2,4dichlorophenol-contaminated groundwater using nano-sized $\mathrm{CaO}_{2}$ in a two-dimensional scale tank. Frontiers of Environmental Science \& Engineering, 15(5): 87

Li Z, Suzuki D, Zhang C, Yoshida N, Yang S, Katayama A (2013). Involvement of Dehalobacter strains in the anaerobic dechlorination of 2,4,6-trichlorophenol. Journal of Bioscience and Bioengineering, 116(5): 602-609

Liang C, Bruell C J, Marley M C, Sperry K L (2004). Persulfate oxidation for in situ remediation of TCE. I. Activated by ferrous ion with and without a persulfate-thiosulfate redox couple. Chemosphere, 55(9): 1213-1223

Liu C S, Higgins C P, Wang F, Shih K (2012). Effect of temperature on oxidative transformation of perfluorooctanoic acid (PFOA) by persulfate activation in water. Separation and Purification Technology, 91: 46-51

Liu F, Fennell D E (2008). Dechlorination and detoxification of 1,2,3,4,7,8-Hexachlorodibenzofuran by a mixed culture containing Dehalococcoidesethenogenes strain 195. Environmental Science \& Technology, 42(2): 602-607

Liu H, Bruton T A, Doyle F A, Sedlak D L (2014b). In Situ chemical oxidation of contaminated groundwater by persulfate: Decomposition by $\mathrm{Fe}(\mathrm{III})$ - and $\mathrm{Mn}(\mathrm{IV})$-containing oxides and aquifer materials. Environmental Science \& Technology, 48(17): 10330-10336

Liu H, Park J W, Häggblom M M (2014a). Enriching for microbial reductive dechlorination of polychlorinated dibenzo-p-dioxins and dibenzofurans. Environmental Pollution, 184: 222-230

Liu J, Wang Y F, Jiang B Q, Wang L H, Chen J Q, Guo H Y, Ji R (2013). Degradation, metabolism, and bound-residue formation and release of tetrabromobisphenol $\mathrm{A}$ in soil during sequential anoxic-oxic incubation. Environmental Science \& Technology, 47(15): 83488354

Liu J W, Wei K H, Xu S W, Cui J, Ma J, Xiao X L, Xi B D, He X S (2021). Surfactant-enhanced remediation of oil-contaminated soil and groundwater: A review. Science of the Total Environment, 756: 144142

Liu S, Guo C, Liang X, Wu F, Dang Z (2016). Nonionic surfactants induced changes in cell characteristics and phenanthrene degradation ability of Sphingomonas sp. GY2B. Ecotoxicology and Environmental Safety, 129: 210-218

Löffler F E, Edwards E A (2006). Harnessing microbial activities for environmental cleanup. Current Opinion in Biotechnology, 17(3): 274-284

Löffler F E, Yan J, Ritalahti K M, Adrian L, Edwards E A, Konstantinidis K T, Muller J A, Fullerton H, Zinder S H, Spormann A M (2013). Dehalococcoides mccartyi gen. nov., sp. nov., obligately organohalide-respiring anaerobic bacteria relevant to halogen cycling and bioremediation, belong to a novel bacterial class, Dehalococcoidia classis nov., order Dehalococcoidales ord. nov. and family 
Dehalococcoidaceae fam. nov., within the phylum chloroflexi. International Journal of Systematic and Evolutionary Microbiology, 63(Pt_2): 625-635

Lombard N J, Ghosh U, Kjellerup B V, Sowers K R (2014). Kinetics and threshold level of 2,3,4,5-tetrachlorobiphenyl dechlorination by an organohalide respiring bacterium. Environmental Science \& Technology, 48(8): 4353-4360

Lu M, Zhang Z, Qiao W, Wei X, Guan Y, Ma Q, Guan Y (2010). Remediation of petroleum-contaminated soil after composting by sequential treatment with Fenton-like oxidation and biodegradation. Bioresource Technology, 101(7): 2106-2113

Lu Q, Qiu L, Yu L, Zhang S, De Toledo R A, Shim H, Wang S (2019). Microbial transformation of chiral organohalides: Distribution, microorganisms and mechanisms. Journal of Hazardous Materials, 368: 849-861

Luo C, Ma J, Jiang J, Liu Y, Song Y, Yang Y, Guan Y, Wu D (2015). Simulation and comparative study on the oxidation kinetics of atrazine by $\mathrm{UV} / \mathrm{H}_{2} \mathrm{O}_{2}, \mathrm{UV} / \mathrm{HSO}_{5}{ }^{-}$and $\mathrm{UV} / \mathrm{S}_{2} \mathrm{O}_{8}{ }^{2-}$. Water Research, 80: $99-108$

Lutze H V, Bircher S, Rapp I, Kerlin N, Bakkour R, Geisler M, Von Sonntag C, Schmidt T C (2015). Degradation of chlorotriazine pesticides by sulfate radicals and the influence of organic matter. Environmental Science \& Technology, 49(3): 1673-1680

Ma J, Zhang Q, Chen F, Zhu Q, Wang Y, Liu G (2020). Remediation of PBDEs-metal co-contaminated soil by the combination of metal stabilization, persulfate oxidation and bioremediation. Chemosphere, 252: 126538

Ma Z, Cao H, Lv F, Yang Y, Chen C, Yang T, Zheng H, Wu D (2021). Preparation of nZVI embedded modified mesoporous carbon for catalytic persulfate to degradation of reactive black 5. Frontiers of Environmental Science \& Engineering, 15(5): 98

Maillard J, Willemin M S (2019). Regulation of organohalide respiration. Advances in Microbial Physiology, 74: 191-238

Mandal S, Bera T, Dubey G, Saha J, Laha J K (2018). Uses of $\mathrm{K}_{2} \mathrm{~S}_{2} \mathrm{O}_{8}$ in metal-catalyzed and metal-free oxidative transformations. ACS Catalysis, 8(6): 5085-5144

Mao X, Jiang R, Xiao W, Yu J (2015). Use of surfactants for the remediation of contaminated soils: A review. Journal of Hazardous Materials, 285: 419-435

Mao X, Oremland R S, Liu T, Gushgari S, Landers A A, Baesman S M, Alvarez-Cohen L (2017). Acetylene fuels tce reductive dechlorination by defined Dehalococcoides/Pelobacter consortia. Environmental Science \& Technology, 51(4): 2366-2372

Maphosa F, van Passel M W J, de Vos W M, Smidt H (2012). Metagenome analysis reveals yet unexplored reductive dechlorinating potential of Dehalobacter sp. E1 growing in co-culture with Sedimentibacter sp. Environmental Microbiology Reports, 4: 604616

Marcet T F, Capiro N L, Yang Y, Löffler F E, Pennell K D (2018). Impacts of low-temperature thermal treatment on microbial detoxification of tetrachloroethene under continuous flow conditions. Water Research, 145: 21-29

Martín-González L, Hatijah Mortan S M, Rosell E, Parladé M, MartínezAlonso N, Gaju G, Caminal L, Adrian E, Marco-Urrea (2015). Stable carbon isotope fractionation during 1,2-dichloropropane-to-propene transformation by an enrichment culture containing Dehalogenimo- nas strains and a $d c p A$ gene. Environmental Science \& Technology, 49(14): 8666-8674

Martínez S, Cuervo-López F M, Gomez J (2007). Toluene mineralization by denitrification in an up flow anaerobic sludge blanket (UASB) reactor. Bioresource Technology, 98(9): 1717-1723

Martínez-Pascual E, Grotenhuis T, Solanas A M, Viñas M (2015). Coupling chemical oxidation and biostimulation: Effects on the natural attenuation capacity and resilience of the native microbial community in alkylbenzene-polluted soil. Journal of Hazardous Materials, 300: 135-143

Mascolo G, Ciannarella R, Balest L, Lopez A (2008). Effectiveness of UV-based advanced oxidation processes for the remediation of hydrocarbon pollution in the groundwater: A laboratory investigation. Journal of Hazardous Materials, 152(3): 1138-1145

Master E R, Lai V W, Kuipers B, Cullen W R, Mohn W W (2002). Sequential anaerobic-aerobic treatment of soil contaminated with weathered Aroclor 1260. Environmental Science \& Technology, 36 (1): 100-103

Matzek L W, Carter K E (2016). Activated persulfate for organic chemical degradation: A review. Chemosphere, 151: 178-188

Maucourt B, Vuilleumier S, Bringel F (2020). Transcriptional regulation of organohalide pollutant utilisation in bacteria. FEMS Microbiology Reviews, 44(2): 189-207

Mayer-Blackwell K, Azizian M F, Green J K, Spormann A M, Semprini L (2017). Survival of vinyl chloride respiring Dehalococcoides mccartyi under long-term electron donor limitation. Environmental Science \& Technology, 51(3): 1635-1642

Moe W M, Reynolds S J, Griffin M A, Mcreynolds J B (2018). Bioremediation strategies aimed at stimulating chlorinated solvent dehalogenation can lead to microbially-mediated toluene biogenesis. Environmental Science \& Technology, 52(16): 9311-9319

Monteagudo J M, Duran A, Latorre J, Exposito A J (2016). Application of activated persulfate for removal of intermediates from antipyrine wastewater degradation refractory towards hydroxyl radical. Journal of Hazardous Materials, 306: 77-86

Mulligan C N, Eftekhari F (2003). Remediation with surfactant foam of PCP-contaminated soil. Engineering Geology, 70(3-4): 269-279

Mulligan C N, Gibbs B F (2004). Types, production and applications of biosurfactants. Proceedings of the Indian National Science Academy. Part B, Biological Sciences, 70(1): 31-55

Nam K, Rodriguez W, Kukor J J (2001). Enhanced degradation of polycyclic aromatic hydrocarbons by biodegradation combined with a modified Fenton reaction. Chemosphere, 45(1): 11-20

Ndjou'ou A C, Bou-Nasr J, Cassidy D (2006). Effect of Fenton reagent dose on coexisting chemical and microbial oxidation in soil. Environmental Science \& Technology, 40(8): 2778-2783

Nelson J L, Jiang J, Zinder S H (2014). Dehalogenation of chlorobenzenes, dichlorotoluenes, and tetrachloroethene by three Dehalobacter spp. Environmental Science \& Technology, 48(7): 3776-3782

Němeček J, Nechanicka M, Spanek R, Eichler F, Zeman J, Cernik M (2019). Engineered in situ biogeochemical transformation as a secondary treatment following ISCO: A field test. Chemosphere, 237: 124460

Nijenhuis I, Kuntze K (2016). Anaerobic microbial dehalogenation of organohalides-state of the art and remediation strategies. Current 
Opinion in Biotechnology, 38: 33-38

Oh W D, Dong Z, Lim T T (2016). Generation of sulfate radical through heterogeneous catalysis for organic contaminants removal: Current development, challenges and prospects. Applied Catalysis B: Environmental, 194: 169-201

Ouyang D, Yan J, Qian L, Chen Y, Han L, Su A, Zhang W, Ni H, Chen M (2017). Degradation of 1,4-dioxane by biochar supported nano magnetite particles activating persulfate. Chemosphere, 184: 609617

Pacwa-Płociniczak M, Plaza G A, Piotrowska-Seget Z, Cameotra S S (2011). Environmental applications of biosurfactants: recent advances. International Journal of Molecular Sciences, 12(1): 633654

Pan X, Yan L, Qu R, Wang Z (2018). Degradation of the UV-filter benzophenone-3 in aqueous solution using persulfate activated by heat, metal ions and light. Chemosphere, 196: 95-104

Pan Y, Chen J, Zhou H, Cheung S G, Tam N F Y (2019). Degradation of BDE-47 in mangrove sediments under alternating anaerobicaerobic conditions. Journal of Hazardous Materials, 378: 120709

Pang Y, Luo K, Tang L, Li X, Yu J, Guo J, Liu Y, Zhang Z, Yue R, Li L (2019). Carbon-based magnetic nanocomposite as catalyst for persulfate activation: A critical review. Environmental Science and Pollution Research International, 26(32): 32764-32776

Pari S, Wang I A, Liu H, Wong B M (2017). Sulfate radical oxidation of aromatic contaminants: a detailed assessment of density functional theory and high-level quantum chemical methods. Environmental Science. Processes \& Impacts, 19(3): 395-404

Parthasarathy A, Stich T A, Lohner S T, Lesnefsky A, Britt R D, Spormann A M (2015). Biochemical and EPR-spectroscopic investigation into heterologously expressed vinyl chloride reductive dehalogenase (VcrA) from Dehalococcoides mccartyi strain VS. Journal of the American Chemical Society, 137(10): 3525-3532

Pathiraja G, Egodawatta P, Goonetilleke A, Te'o V S J (2019). Effective degradation of polychlorinated biphenyls by a facultative anaerobic bacterial consortium using alternating anaerobic aerobic treatments. Science of the Total Environment, 659: 507-514

Peng H, Zhang W, Xu L, Fu R, Lin K (2016). Oxidation and mechanism of decabromodiphenyl ether (BDE209) by thermally activated persulfate (TAP) in a soil system. Chemical Engineering Journal, 306: 226-232

Petri B G, Watts R J, Tsitonaki A, Crimi M, Thomson N R, Teel T L (2011). Fundamentals of ISCO Using Persulfate. In: Siegrist R, Crimi M, Simpkin T, eds. In situ Chemical Oxidation for Groundwater Remediation. SERDP/ESTCP Environmental Remediation Technology, 3 (Springer, New York, NY): 147-192

Pöritz M, Schiffmann C L, Hause G, Heinemann U, Seifert J, Jehmlich N, Von Bergen M, Nijenhuis I, Lechner U (2015). Dehalococcoides mecartyi strain DCMB5 respires a broad spectrum of chlorinated aromatic compounds. Applied and Environmental Microbiology, 81 (2): 587-596

Puentes Jácome L A, Wang P H, Molenda O, Li Y X, Islam M A, Edwards E A (2019). Sustained dechlorination of vinyl chloride to ethene in Dehalococcoides-enriched cultures grown without addition of exogenous vitamins and at low pH. Environmental Science \& Technology, 53(19): 11364-11374

Qian Y, Guo X, Zhang Y, Peng Y, Sun P, Huang C H, Niu J, Zhou X,
Crittenden J C (2016). Perfluorooctanoic acid degradation using UVpersulfate process: Modeling of the degradation and chlorate formation. Environmental Science \& Technology, 50(2): 772-781

Qiao W, Puentes Jácome L A, Tang X, Lomheim L, Yang M I, Gaspard S, Avanzi I R, Wu J, Ye S, Edwards E A (2020). Microbial communities associated with sustained anaerobic reductive dechlorination of alpha-, beta-, gamma-, and delta-hexachlorocyclohexane isomers to monochlorobenzene and benzene. Environmental Science \& Technology, 54(1): 255-265

Ranck J M, Bowman R S, Weeber J L, Katz L E, Sullivan E J (2005). BTEX removal from produced water using surfactant-modified zeolite. Journal of Environmental Engineering, 131(3): 434-442

Rastogi A, Al-Abed S R, Dionysiou D D (2009). Sulfate radical-based ferrous-peroxymonosulfate oxidative system for PCBs degradation in aqueous and sediment systems. Applied Catalysis B: Environmental, 85(3-4): 171-179

Richardson R E (2013). Genomic insights into organohalide respiration. Current Opinion in Biotechnology, 24(3): 498-505

Rieger P G, Meier H M, Gerle M, Vogt U, Groth T, Knackmuss H J (2002). Xenobiotics in the environment: present and future strategies to obviate the problem of biological persistence. Journal of Biotechnology, 94(1): 101-123

Rios L E, David M, Vazquez-Arenas J, Anderson W A (2013). Use of surfactants and blends to remove DDT from contaminated soils. Canadian Journal of Chemical Engineering, 91(2): 238-244

Ritalahti K M, Löffler F E, Rasch E E, S. K S (2005). Bioaugmentation for chlorinated ethene detoxification bioaugmentation and molecular diagnostics in the bioremediation of chlorinated ethene-contaminated sites. Industrial Biotechnology, 1: 114-118

Rodenburg L A, Krumins V, Curran J C (2015). Microbial dechlorination of polychlorinated biphenyls, dibenzo- $p$-dioxins, and-furans at the Portland Harbor Superfund site, Oregon, USA. Environmental Science \& Technology, 49(12): 7227-7235

Rodriguez S, Santos A, Romero A (2017). Oxidation of priority and emerging pollutants with persulfate activated by iron: Effect of iron valence and particle size. Chemical Engineering Journal, 318: 197205

Ronen Z, Abeliovich A (2000). Anaerobic-aerobic process for microbial degradation of Tetrabromobisphenol A. Applied and Environmental Microbiology, 66(6): 2372-2377

Rosell M, Palau J, Mortan S H, Caminal G, Soler A, Shouakar-Stash O, Marco-Urrea E (2019). Dual carbon-chlorine isotope fractionation during dichloroelimination of 1,1,2-trichloroethane by an enrichment culture containing Dehalogenimonas sp. Science of the Total Environment, 648: 422-429

Roy A, Dutta A, Pal S, Gupta A, Sarkar J, Chatterjee A, Saha A, Sarkar P, Sar P, Kazy S K (2018). Biostimulation and bioaugmentation of native microbial community accelerated bioremediation of oil refinery sludge. Bioresource Technology, 253: 22-32

Rybnikova V, Usman M, Hanna K (2016). Removal of PCBs in contaminated soils by means of chemical reduction and advanced oxidation processes. Environmental Science and Pollution Research International, 23(17): 17035-17048

Sadowsky D, Mcneill K, Cramer C J (2013). Thermochemical factors affecting the dehalogenation of aromatics. Environmental Science \& Technology, 47(24): 14194-14203 
Sahl J, Munakata-Marr J (2006). The effects of in situ chemical oxidation on microbiological processes: A review. Remediation Journal, 16(3): 57-70

Schubert T, Adrian L, Sawers R G, Diekert G (2018). Organohalide respiratory chains: composition, topology and key enzymes. FEMS Microbiology Ecology, 94(4)

Sharma B M, Bharat G K, Tayal S, Nizzetto L, Cupr P, Larssen T (2014). Environment and human exposure to persistent organic pollutants (POPs) in India: A systematic review of recent and historical data. Environment International, 66: 48-64

Siddaramappa S, Challacombe J F, Delano S F, Green L D, Daligault H, Bruce D, Detter C, Tapia R, Han S, Goodwin L, Han J, Woyke T, Pitluck S, Pennacchio L, Nolan M, Land M, Chang Y J, Kyrpides N C, Ovchinnikova G, Hauser L, Lapidus A, Yan J, Bowman K S, Da Costa M S, Rainey F A, Moe W M (2012). Complete genome sequence of Dehalogenimonas lykanthroporepellens type strain (BLDC-9(T)) and comparison to "Dehalococcoides" strains. Standards in Genomic Sciences, 6(2): 251-264

Sowers K R, May H D (2013). In situ treatment of PCBs by anaerobic microbial dechlorination in aquatic sediment: Are we there yet? Current Opinion in Biotechnology, 24(3): 482-488

Sutton N B, Atashgahi S, Van Der Wal J, Wijn G, Grotenhuis T, Smidt H, Rijnaarts H H (2015). Microbial dynamics during and after in situ chemical oxidation of chlorinated solvents. Ground Water, 53(2): 261-270

Sutton N B, Grotenhuis J T C, Langenhoff A A M, Rijnaarts H H M (2011). Efforts to improve coupled in situ chemical oxidation with bioremediation: A review of optimization strategies. Journal of Soils and Sediments, 11(1): 129-140

Sutton N B, Grotenhuis T, Rijnaarts H H (2014a). Impact of organic carbon and nutrients mobilized during chemical oxidation on subsequent bioremediation of a diesel-contaminated soil. Chemosphere, 97: 64-70

Sutton N B, Langenhoff A A, Lasso D H, Van Der Zaan B, Van Gaans P, Maphosa F, Smidt H, Grotenhuis T, Rijnaarts H H (2014b). Recovery of microbial diversity and activity during bioremediation following chemical oxidation of diesel contaminated soils. Applied Microbiology and Biotechnology, 98(6): 2751-2764

Tan J, Li Z, Li J, Wu J, Yao X, Zhang T (2021). Graphitic carbon nitridebased materials in activating persulfate for aqueous organic pollutants degradation: A review on materials design and mechanisms. Chemosphere, 262: 127675

Tang S, Chan W W, Fletcher K E, Seifert J, Liang X, Löffler F E, Edwards E A, Adrian L (2013). Functional characterization of reductive dehalogenases by using blue native polyacrylamide gel electrophoresis. Applied and Environmental Microbiology, 79(3): 974-981

Tang X, Hashmi M Z, Zeng B, Yang J, Shen C (2015). Application of iron-activated persulfate oxidation for the degradation of PCBs in soil. Chemical Engineering Journal, 279: 673-680

Teel A L, Ahmad M, Watts R J (2011). Persulfate activation by naturally occurring trace minerals. Journal of Hazardous Materials, 196: 153159

Townsend G T, Suflita J M (1997). Influence of sulfur oxyanions on reductive dehalogenation activities in Desulfomonile tiedjei. Applied and Environmental Microbiology, 63(9): 3594-3599
Tsitonaki A, Petri B, Crimi M, Mosbæk H, Siegrist R L, Bjerg P L (2010). In situ chemical oxidation of contaminated soil and groundwater using persulfate: A review. Critical Reviews in Environmental Science and Technology, 40(1): 55-91

Tsitonaki A, Smets B F, Bjerg P L (2008). Effects of heat-activated persulfate oxidation on soil microorganisms. Water Research, 42(45): 1013-1022

Tsuneta T, Loch-Caruso R, Quensen J F III, Boyd S A, Hanna M, Grindatti C (2008). Stimulatory effects of a microbially dechlorinated polychlorinated biphenyl (PCB) mixture on rat uterine contraction in vitro. Environmental Research, 107(2): 185-193

Türkowsky D, Jehmlich N, Diekert G, Adrian L, Von Bergen M, Goris T (2018). An integrative overview of genomic, transcriptomic and proteomic analyses in organohalide respiration research. FEMS Microbiology Ecology, 94(3)

Tyagi M, Da Fonseca M M, De Carvalho C C (2011). Bioaugmentation and biostimulation strategies to improve the effectiveness of bioremediation processes. Biodegradation, 22(2): 231-241

Uenotsuchi T, Nakayama J, Asahi M, Kohro O, Akimoto T, Muto M, Shimizu K, Katayama I, Kanzaki T, Kanagawa Y, Imamura T, Furue M (2005). Dermatological manifestations in Yusho: Correlation between skin symptoms and blood levels of dioxins, such as polychlorinated dibenzofurans (PCDFs) and polychlorinated biphenyls (PCBs). Journal of Dermatological Science. Supplement, 1(1): S73-S80

Vakili M, Qiu W, Cagnetta G, Huang J, Yu G (2021). Solvent-free mechanochemical mild oxidation method to enhance adsorption properties of chitosan. Frontiers of Environmental Science \& Engineering, 15(6): 128

Venny S, Gan H K, Ng (2012). Modified Fenton oxidation of polycyclic aromatic hydrocarbon (PAH)-contaminated soils and the potential of bioremediation as post-treatment. Science of the Total Environment, 419: 240-249

Villa R D, Trovó A G, Nogueira R F P (2010). Soil remediation using a coupled process: soil washing with surfactant followed by photoFenton oxidation. Journal of Hazardous Materials, 174(1-3): 770775

Wacławek S, Lutze H V, Grübel K, Padil V V T, Černík M, Dionysiou D D (2017). Chemistry of persulfates in water and wastewater treatment: A review. Chemical Engineering Journal, 330: 44-62

Waldemer R H, Tratnyek P G, Johnson R L, Nurmi J T (2007). Oxidation of chlorinated ethenes by heat-activated persulfate_kinetics and products. Environmental Science \& Technology, 41: 1010-1015

Wallace S, Kadlec R (2005). BTEX degradation in a cold-climate wetland system. Water Science and Technology, 51(9): 165-171

Wang S, Chen C, Zhao S, He J (2019). Microbial synergistic interactions for reductive dechlorination of polychlorinated biphenyls. Science of the Total Environment, 666: 368-376

Wang S, Chng K R, Chen C, Bedard D L, He J (2015). Genomic characterization of Dehalococcoidesmccartyi strain JNA that reductively dechlorinates tetrachloroethene and polychlorinated biphenyls. Environmental Science \& Technology, 49(24): 14319-14325

Wang S, Chng K R, Wilm A, Zhao S, Yang K L, Nagarajan N, He J (2014). Genomic characterization of three unique Dehalococcoides that respire on persistent polychlorinated biphenyls. Proceedings of the National Academy of Sciences of the United States of America, 
111(33): 12103-12108

Wang S, He J (2013). Phylogenetically distinct bacteria involve extensive dechlorination of aroclor 1260 in sediment-free cultures. PLoS One, 8(3): e59178

Wang S, Qiu L, Liu X, Xu G, Siegert M, Lu Q, Juneau P, Yu L, Liang D, He Z, Qiu R (2018). Electron transport chains in organohaliderespiring bacteria and bioremediation implications. Biotechnology Advances, 36(4): 1194-1206

Wang Y, Chen S Y, Yang X, Huang X F, Yang Y H, He E K, Wang S, Qiu R L (2017). Degradation of 2,2',4,4'-tetrabromodiphenyl ether (BDE-47) by a nano zerovalent iron-activated persulfate process: The effect of metal ions. Chemical Engineering Journal, 317: 613-622

Wardman P (1989). Reduction potentials of one-electron couples involving free radicals in aqueous-solution. Journal of Physical and Chemical Reference Data, 18(4): 1637-1755

Watson K G, Serban A (1995). Evaluation of the Elbs persulfate oxidation reaction for the preparation of aryloxyphenoxypropionate herbicides. Australian Journal of Chemistry, 48(8): 1503-1509

Watts R J, Ahmad M, Hohner A K, Teel A L (2018). Persulfate activation by glucose for in situ chemical oxidation. Water Research, 133: 247254

Whalen M M, Loganathan B G, Yamashita N, Saito T (2003). Immunomodulation of human natural killer cell cytotoxic function by triazine and carbamate pesticides. Chemico-Biological Interactions, 145(3): 311-319

Willemin M S, Vingerhoets M, Holliger C, Maillard J (2020). Hybrid transcriptional regulators for the screening of target DNA motifs in organohalide-respiring bacteria. Frontiers in Microbiology, 11: 310

Williams R, Doeschate M T, Curnick D J, Brownlow A, Barber J L, Davison N J, Deaville R, Perkins M, Jepson P D, Jobling S (2020). Levels of polychlorinated biphenyls are still associated with toxic effects in harbor porpoises (Phocoena) despite having fallen below proposed toxicity thresholds. Environmental Science \& Technology, 54(4): 2277-2286

Wu Q, Watts J E, Sowers K R, May H D (2002). Identification of a bacterium that specifically catalyzes the reductive dechlorination of polychlorinated biphenyls with doubly flanked chlorines. Applied and Environmental Microbiology, 68(2): 807-812

Wu X, Gu X, Lu S, Qiu Z, Sui Q, Zang X, Miao Z, Xu M (2015). Strong enhancement of trichloroethylene degradation in ferrous ion activated persulfate system by promoting ferric and ferrous ion cycles with hydroxylamine. Separation and Purification Technology, 147: 186193

Xia Y, Cheng Y, Li L, Chen Y, Jiang Y (2020). A microcosm study on persulfate oxidation combined with enhanced bioremediation to remove dissolved BTEX in gasoline-contaminated groundwater. Biodegradation, 31(3): 213-222

Xu G, Lu Q, Yu L, Wang S (2019). Tetrachloroethene primes reductive dechlorination of polychlorinated biphenyls in a river sediment microcosm. Water Research, 152: 87-95

Xu Y, Gregory K B, Vanbriesen J M (2018). Effects of ferric oxyhydroxide on anaerobic microbial dechlorination of polychlorinated biphenyls in Hudson and Grasse River sediment microcosms: dechlorination extent, preferences, ortho removal, and its enhancement. Frontiers in Microbiology, 9: 1574

Xu Y, Yu R M, Zhang X, Murphy M B, Giesy J P, Lam M H, Lam P K,
$\mathrm{Wu} \mathrm{R} \mathrm{S}$, Yu H (2006). Effects of $\mathrm{PCBs}$ and $\mathrm{MeSO}_{2}-\mathrm{PCBs}$ on adrenocortical steroidogenesis in $\mathrm{H} 295 \mathrm{R}$ human adrenocortical carcinoma cells. Chemosphere, 63(5): 772-784

Yan J, Han L, Gao W, Xue S, Chen M (2015). Biochar supported nanoscale zerovalent iron composite used as persulfate activator for removing trichloroethylene. Bioresource Technology, 175: 269274

Yang C, Kublik A, Weidauer C, Seiwert B, Adrian L (2015). Reductive dehalogenation of oligocyclic phenolic bromoaromatics by Dehalococcoides mccartyi Strain CBDB1. Environmental Science \& Technology, 49(14): 8497-8505

Yang X, Beckmann D, Fiorenza S, Niedermeier C (2005). Field study of pulsed air sparging for remediation of petroleum hydrocarbon contaminated soil and groundwater. Environmental Science \& Technology, 39(18): 7279-7286

Yang S, Cheng J, Sun J, Hu Y, Liang X (2013). Defluorination of aqueous perfluorooctanesulfonate by activated persulfate oxidation. PLoS One, 8(10): e74877

Yang Y, Capiro N L, Marcet T F, Yan J, Pennell K D, Löffler F E (2017a). Organohalide respiration with chlorinated ethenes under low pH conditions. Environmental Science \& Technology, 51(15): 85798588

Yang Y, Higgins S A, Yan J, Simsir B, Chourey K, Iyer R, Hettich R L, Baldwin B, Ogles D M, Löffler F E (2017b). Grape pomace compost harbors organohalide-respiring Dehalogenimonas species with novel reductive dehalogenase genes. ISME Journal, 11(12): 2767-2780

Yao C, Zhang Y, Du M, Du X, Huang S (2019). Insights into the mechanism of non-radical activation of persulfate via activated carbon for the degradation of p-chloroaniline. Chemical Engineering Journal, 362: 262-268

Guvenc S Y, Varank G (2021). Degradation of refractory organics in concentrated leachate by the Fenton process: Central composite design for process optimization. Frontiers of Environmental Science \& Engineering, 15(1): 2

Yukselen-Aksoy Y, Reddy K R (2012). Effect of soil composition on electrokinetically enhanced persulfate oxidation of polychlorobiphenyls. Electrochimica Acta, 86: 164-169

Yin Y, Yan J, Chen G, Murdoch F K, Pfisterer N, Löffler F E (2019). Nitrous oxide is a potent inhibitor of bacterial reductive dechlorination. Environmental Science \& Technology, 53(2): 692-701

Yoshikawa M, Zhang M, Toyota K (2017). Integrated anaerobic-aerobic biodegradation of multiple contaminants including chlorinated ethylenes, benzene, toluene, and dichloromethane. Water, Air, and Soil Pollution, 228(1): 25

Yu L, Lu Q, Qiu L, Xu G, Zeng Y, Luo X, Wang S, Mai B (2018). Enantioselective dechlorination of polychlorinated biphenyls in Dehalococcoides mccartyi CG1. Applied and Environmental Microbiology, 84(21): e01300-18

Yu Z Y, Wang W H, Song L, Lu L Q, Wang Z Y, Jiang X F, Dong C N, Qiu R Y (2013). Acceleration comparison between $\mathrm{Fe}^{2+} / \mathrm{H}_{2} \mathrm{O}_{2}$ and $\mathrm{Co}^{2+}$ /oxone for decolouration of azo dyes in homogeneous systems. Chemical Engineering Journal, 234: 475-483

Yuan S, Liao P, Alshawabkeh A N (2014). Electrolytic manipulation of persulfate reactivity by iron electrodes for trichloroethylene degradation in groundwater. Environmental Science \& Technology, 48(1): 656-663 
Yuan Y, Tao H, Fan J, Ma L (2015). Degradation of $p$-chloroaniline by persulfate activated with ferrous sulfide ore particles. Chemical Engineering Journal, 268: 38-46

Zhai X, Hua I, Rao P S C, Lee L S (2006). Cosolvent-enhanced chemical oxidation of perchloro-ethylene by potassium permanganate. Journal of Contaminant Hydrology, 82(1-2): 61-74

Zhang B, Guo Y, Huo J, Xie H, Xu C, Liang S (2020). Combining chemical oxidation and bioremediation for petroleum polluted soil remediation by BC-nZVI activated persulfate. Chemical Engineering Journal, 382: 123055

Zhang B T, Zhang Y, Teng Y, Fan M (2015). Sulfate radical and its application in decontamination technologies. Critical Reviews in Environmental Science and Technology, 45(16): 1756-1800

Zhang T, Chen Y, Wang Y, Le Roux J, Yang Y, Croue J P (2014). Efficient peroxydisulfate activation process not relying on sulfate radical generation for water pollutant degradation. Environmental Science \& Technology, 48(10): 5868-5875

Zhang T, Zhu H, Croue J P (2013). Production of sulfate radical from peroxymonosulfate induced by a magnetically separable $\mathrm{CuFe}_{2} \mathrm{O}_{4}$ spinel in water: Efficiency, stability, and mechanism. Environmental Science \& Technology, 47(6): 2784-2791

Zhang Z F, Zhong L, White M D, Szecsody J E (2012). Experimental investigation of the effective foam viscosity in unsaturated porous media. Vadose Zone Journal, 11(4): 9

Zhao S, Ding C, He J (2015). Detoxification of 1,1,2-trichloroethane to ethene by desulfitobacterium and identification of its functional reductase gene. PLoS One, 10(4): e0119507

Zhao S, He J (2019). Reductive dechlorination of high concentrations of chloroethenes by a Dehalococcoides mccartyi strain 11G. FEMS Microbiology Ecology, 95(1)

Zhen H, Du S, Rodenburg L A, Mainelis G, Fennell D E (2014). Reductive dechlorination of 1,2,3,7,8-pentachlorodibenzo-p-dioxin and Aroclor 1260, 1254 and 1242 by a mixed culture containing Dehalococcoides mccartyi strain 195. Water Research, 52: 51-62

Zhi D, Lin Y, Jiang L, Zhou Y, Huang A, Yang J, Luo L (2020).
Remediation of persistent organic pollutants in aqueous systems by electrochemical activation of persulfates: A review. Journal of Environmental Management, 260: 110125

Zhou P, Zhang J, Zhang Y, Zhang G, Li W, Wei C, Liang J, Liu Y, Shu S (2018). Degradation of 2,4-dichlorophenol by activating persulfate and peroxomonosulfate using micron or nanoscale zero-valent copper. Journal of Hazardous Materials, 344: 1209-1219

Zhu C, Fang G, Dionysiou D D, Liu C, Gao J, Qin W, Zhou D (2016b). Efficient transformation of DDTs with Persulfate Activation by Zerovalent Iron Nanoparticles: A Mechanistic Study. Journal of Hazardous Materials, 316: 232-241

Zhu C, Zhu F, Dionysiou D D, Zhou D, Fang G, Gao J (2018a). Contribution of alcohol radicals to contaminant degradation in quenching studies of persulfate activation process. Water Research, 139: $66-73$

Zhu C, Zhu F, Liu C, Chen N, Zhou D, Fang G, Gao J (2018b). Reductive hexachloroethane degradation by $\mathrm{S}_{2} \mathrm{O}_{8}{ }^{--}$with thermal activation of persulfate under anaerobic conditions. Environmental Science \& Technology, 52(15): 8548-8557

Zhu S, Huang X, Ma F, Wang L, Duan X, Wang S (2018c). Catalytic removal of aqueous contaminants on $\mathrm{N}$-doped graphitic biochars: Inherent roles of adsorption and nonradical mechanisms. Environmental Science \& Technology, 52(15): 8649-8658

Zhu S, Li X, Kang J, Duan X, Wang S (2019a). Persulfate activation on crystallographic manganese oxides: Mechanism of singlet oxygen evolution for nonradical selective degradation of aqueous contaminants. Environmental Science \& Technology, 53(1): 307-315

Zhu X, Du E, Ding H, Lin Y, Long T, Li H, Wang L (2016a). QSAR modeling of VOCs degradation by ferrous-activated persulfate oxidation. Desalination and Water Treatment, 57(27): 1254612560

Zhu X, Zhong Y, Wang H, Li D, Deng Y, Peng P (2019b). New insights into the anaerobic microbial degradation of decabrominated diphenyl ether (BDE-209) in coastal marine sediments. Environmental Pollution, 255: 113151 